\title{
Abstracts from Venom Week 2009, June 1-4, 2009 Albuquerque, NM
}

\author{
Steven A. Seifert \\ Published online: 13 July 2010 \\ (C) American College of Medical Toxicology 2010
}

\section{RANDOMISED DOUBLE-BLIND TRIAL OF TWO NEW ANTIVENOMS FOR ENVENOMING BY SAW- SCALED OR CARPET VIPERS (ECHIS OCELLATUS) IN NIGERIA}

Abubakar IS ${ }^{(1)}$, Abubakar $\mathrm{SB}^{(2)}$, Habib $\mathrm{AG}^{(3)}$, Nasidi $\mathrm{A}^{(4)}$, Durfa $\mathrm{N}^{(4)}$, Yusuf $\mathrm{PO}^{(5)}$, Larnyang $\mathrm{S}^{(6)}$, Garnvwa $\mathrm{J}^{(7)}$, Sokomba $\mathrm{E}^{(8)}$, Theakston $\mathrm{RDG}^{(7)}$, Salako $\mathrm{L}^{(9)}$, Juszczak $\mathrm{E}^{(10)}$, Alder $\mathrm{N}^{(10)}$, Warrell $\mathrm{DA}^{(7,11)}$, for the Nigeria-UK EchiTab Study Group.

1. Department of Community Medicine, Bayero University of Kano, Nigeria

2. General Hospital Kaltungo, Gombe State, Nigeria

3. Department of Medicine, Bayero University Kano, Nigeria

4. Special Projects Unit, Federal Ministry of Health, Abuja Nigeria

5. Faculty of Veterinary Medicine, Ahmadu Bello University Zaria, Nigeria

6. Deceased, formerly of Department of Community Health, University of Jos, Nigeria

7. Alistair Reid Venom Research Unit, Liverpool School of Tropical Medicine, Liverpool, UK

8. Department of Pharmacology, University of Jos, Nigeria

9. Department of Pharmacology and Therapeutics, University of Ibadan, Nigeria

10. Centre for Statistics in Medicine, University of Oxford

11. Nuffield Department of Clinical Medicine, John Radcliffe Hospital, University of Oxford, UK

david.warrell@ndm.ox.ac.uk

Background: In the West African savanna region, envenoming by Echis ocellatus is the leading cause of snake bite morbidity and mortality, but effective antivenoms are scarce and expensive.

\footnotetext{
S. A. Seifert $(\bowtie)$

University of New Mexico School of Medicine,

Albuquerque, NM, USA

e-mail: sseifert@salud.unm.edu
}

Methods: Two new whole $\operatorname{IgG}$ antivenoms, purified using caprylic-acid, passed pre-clinical and preliminary clinical dose-finding/safety testing: Instituto Clodomiro Picado, Costa Rica "EchiTAb Plus" (ET-Plus) E. ocellatus, Naja nigricollis, Bitis arietans trispecific antivenom and MicroPharm, UK "EchiTAb G” (ET-G) E. ocellatus monospecific antivenom. They were compared in a randomized, doubleblind, controlled, non-inferiority trial in Kaltungo Hospital, NE Nigeria.

Results and Discussion: Four hundred snake bite patients with incoagulable blood indicative of $E$. ocellatus envenoming were randomized for treatment with initial doses of three vials of ET-Plus (194) or one vial of ET-G (206). The two groups of patients were similar in their presenting clinical features and delay between bite and treatment. Visible spontaneous systemic bleeding ceased within $32 \mathrm{~min}$ of the first dose of antivenom in all cases. Permanent restoration of blood coagulability at $6 \mathrm{~h}$ by the initial doses was achieved in 161/194 (83.0\%) of ET-Plus and 156/206 (75.7\%) of ET-G-treated patients (RR, 1.10 $95 \% 1$-sided CI 1.01 to $\ddot{y} ; P=0.05$ ) establishing not only non-inferiority, but also superiority of ET-Plus. However, ET-Plus caused one or more reaction on significantly more occasions than did ET-G [50/194 (25.8\%) and 39/206 (18.9\%); respectively, RR $1.1095 \%$ one-sided CI 1.01 to $\ddot{\mathrm{y}} ; P=0.05]$. ET-Plus also caused severe reactions (bronchospasm/GI symptoms) on significantly more occasions than did ET-G [21/194 (10.8\%) and 11/206 (4.1\%), respectively; RR, 2.03 95\% one-sided CI upper limit 3.66; $P=0.03]$. There were no fatalities. Median length of hospital stay was similar for both antivenoms. Seven out of 194 (3.6\%) patients treated with ET-Plus and 15/206 (7.3\%) ET-G developed necrosis during their hospital admission [RR, $0.5095 \%$ one-sided CI upper limit 1.03; $P=0.08]$.

Conclusion: In an initial dose of three vials, ET-Plus proved superior to one vial of ET-G in restoring blood coagulability after $6 \mathrm{~h}$, and it had the advantage of specificity against venoms of two other species of major importance in West Africa, N. nigricollis and B. arietans. 
However, ET-Plus caused more frequent and more severe early reaction than ET-G. Both antivenoms can be recommended for the treatment of $E$. ocellatus envenoming in Nigeria and perhaps elsewhere in West Africa.

\section{RECENT ADVANCES IN VENOM ANALYSIS}

\author{
Alagón A. \\ Instituto de Biotecnologia-UNAM, Cuernavaca, México \\ alagon@ibt.unam.mx
}

In the past years, we developed and validated several ELISAs to measure venom as well as antivenom levels in human and animal model samples and applied them in clinical trials and basic research. A capture antibody removes the corresponding venom antigens from the biological sample; then, a detection and a secondary antibody serve to measure the bound venom antigens. With an ELISA for Centruroides venom with a lower limit of quantification of $1 \mathrm{ng} / \mathrm{mL}$, we showed that clinical resolution of scorpion envenomation in children treated with antivenom correlates with the disappearance of venom antigens in plasma (NEJM, 2009, 360:2090-2098). In a study of rattlesnake envenomation, the use of a sensitive ELISA was seminal to establish that recurrent hypofibrinogenemia and thrombocytopenia are associated with recurrent venom antigen detection in plasma. Accordingly, we favor the notion, as pointed out by Professor David Theakston more than a decade ago (Ann Trop Med Parasitol, 1997, 91:857-865), that the disappearance of venom antigenemia following antivenom administration is a valid endpoint to objectively measure the efficacy of antivenom.

More recently, we developed an ELISA for the detection of Loxosceles sphingomyelinase D (SMD) in skin lesions. Skin ulcers produced by Loxosceles bites are often confused with other types of lesions potentially leading to incorrect treatment. Definitive diagnosis is problematic because patients generally do not bring the offending spider to the clinicians for identification. Our objective was to develop a specific and sensitive assay to determine minute amounts of Loxosceles SMD in biological samples, thus providing a reliable method for specific diagnosis. A monoclonal antibody (5C10) against Loxosceles boneti recombinant SMD capable of high-affinity binding to SMDs from all North American Loxosceles species tested so far (ten, including Loxosceles reclusa) was used to capture the antigen; the antigen was then detected by a specific anti- $L$. reclusa SMD horse polyclonal serum followed by incubation with goat anti-horse peroxidase conjugate. The ELISA assay had a lower limit of detection of $10.6 \mathrm{pg}$ and a lower limit of quantitation of $30.4 \mathrm{pg}$. SMD detection experiments were performed in rabbits after intradermal injections with 6 or $12 \mathrm{mcg}$ of L. reclusa recombinant SMD. Surface skin swab specimens were taken from the inflamed area by using a cotton swab moistened with PBS. SMD was recovered by gently rubbing the area for about $1 \mathrm{~min}(\mathrm{~J} A m$ Acad Dermatol, 2006, 55:888-890). Samples were kept frozen at $-20^{\circ} \mathrm{C}$ enclosed in $15-\mathrm{ml}$ plastic-capped tubes. The absorbed material was eluted by centrifugation at $18,000 \mathrm{~g}$ for $2 \mathrm{~min}$ in a $1.5-\mathrm{ml}$ microcentrifuge tube. SMD was easily detected after $96 \mathrm{~h}$ post-injection (30-350 pg), and most rabbits had measurable toxin after 7 days. Human samples from 21 patients with suspicious skin lesions were also tested; six of them were positive and were treated with antivenom $\left(\operatorname{Loxmyn}^{\circledR}\right)$.

\section{CIGUATOXIN AND TETRODOTOXIN IN FISH EGGS: IMPLICATIONS FOR EVOLUTION AND PUBLIC HEALTH}

Alcock J.

New Mexico VA Healthcare System, Emergency Medicine Service, and University of New Mexico, Department of Emergency Medicine, Albuquerque NM, USA

joealcock@gmail.com

Introduction: Pufferfish and fish affected by ciguatera share commonalities in the processing of exogenous biological neurotoxins. Both ciguatera and pufferfish tetrodotoxin toxidromes are characterized as resulting from accumulation and amplification of microbe-derived toxins as they move up the food chain. The food chain explanation is incomplete, however, because both fish embryos and juveniles contain toxins in high concentrations. Also unexplained are patterns of toxin accumulation within the flesh and viscera of affected fish, particularly the preferential accumulation of toxin in the ovaries in these species. Toxin distribution in adult fish: The concentration of toxin in the ovaries and viscera in fish differs from other toxic organisms, such as the monarch butterfly. Monarch butterflies accumulate of cardiac glycosides from milkweed as larvae. Monarchs concentrate toxins in peripheral tissues more than their abdomen and thorax. Frequent beak marks on monarch wings indicate that they can be tasted but not killed by bird predators. This pattern suggests that individual selection, not group selection, may have led to the evolution of toxin concentration in monarch butterflies. Neurotoxic fish, by contrast, have low concentrations of ciguatoxin and TTX in the skin and muscle as adults. Predators have little means to discriminate among toxic and nontoxic fish by taste. Thus, toxins are unlikely to protect individual adult fish. The tissue distribution of ciguatoxin and TTX argues for another benefit at an earlier stage in the fish lifecycle. Adult fish deliver toxin 
to immature offspring via the oocyte. In both ciguatera and pufferfish, the ovary is the site of the highest concentration of toxin. The liver usually demonstrates high toxicity, except in the spawning season, when the ovary becomes toxic by accumulating TTX transferred from the liver. Ovary toxicity is highest when the ova are maturing. In ciguatoxin-bearing fish and pufferfish, the ovary has greater toxicity than the testes. In pufferfish, the testes join the skin as tissue with the least toxin concentration.

Toxin in eggs and juveniles: An adult female will derive a selective advantage if a larger proportion of her offspring survive to reproductive maturity. Because eggs are spatially clustered, a few unpalatable eggs may be sacrificed to spare the remainder of an egg brood. Species that concentrate TTX and ciguatera toxins may have a selective advantage that accrues from a decrease in predation of eggs and juveniles. In both ciguatera and pufferfish, toxin is concentrated in embryos. TTX has been demonstrated in pufferfish juveniles. Eating pufferfish eggs has resulted in human fatalities. Ciguatera has resulted from eating as few as three barracuda eggs. What harms humans may benefit fish at the earliest stage of their life cycle, however. Pufferfish eggs are rejected by predators. Pufferfish juveniles are mouthed by predators and spit out, apparently unharmed. This work implies that pufferfish juveniles have a high concentration of toxin in their skin, unlike adults.

Summary and clinical implications: Similarities in ciguatera and TTX in pufferfish may reflect convergent evolution. Fish in both groups develop a pattern of toxin distribution in adults that promotes toxin delivery to offspring, with probable effects on embryonic and juvenile survival. Natural selection may favor increased delivery of toxin to offspring when it is available in the environment. From a health perspective, ciguatera is an increasingly recognized public health problem, but the danger of neurotoxins in fish eggs is rarely mentioned. Educational material from the CDC and elsewhere document the foodchain mechanism of toxin accumulation and advise against eating large specimens of reef fish. Public health education should emphasize the potential danger of eating roe and juvenile fish in addition to the current warnings.

Table 1. Similarities between ciguatoxin and pufferfish tetrodotoxin

\begin{tabular}{|c|c|c|c|c|}
\hline $\begin{array}{l}\text { Fish } \\
\text { syndrome }\end{array}$ & $\begin{array}{l}\text { Viscera }>\text { skin } \\
\text { (adults) }\end{array}$ & $\begin{array}{l}\text { Ovary }>\text { testes } \\
\text { (adults) }\end{array}$ & $\begin{array}{l}\text { Toxic } \\
\text { eggs }\end{array}$ & $\begin{array}{l}\text { Juveniles } \\
\text { rejected by } \\
\text { predators }\end{array}$ \\
\hline Ciguatera & Yes & Yes & Yes & Unknown \\
\hline Tetrodotoxin & Yes & Yes & Yes & Yes \\
\hline
\end{tabular}

\section{ARE VENOM CHARACTERISTICS OF NORTH AMERICAN BROWN SPIDERS (LOXOSCELES) PREDICTABLE BASED ON SPECIES RELATIONSHIPS?}

Binford GJ.

Lewis \& Clark College, Portland, OR, USA binford@lclark.edu

Background: Spiders in the family Sicariidae including brown spiders (Loxosceles) and six-eyed sand spiders (Sicarius) are famous for bites that cause dermonecrotic lesions in mammalian tissues. The toxin sphingomyelinase D (SMase D) in venoms of these animals is a sufficient causative agent for lesion formation in animal models. This toxin is a member of a gene family (SicTox), and multiple different genes that vary in substrate specificity are expressed in single species. Given their direct clinical relevance, understanding patterns of variation of the SMase $\mathrm{D}$ gene family across species is central to knowing which species are capable of causing lesions when they bite and developing broadly effective diagnostics and treatments. Fundamental to making sense of patterns of variation in venom is understanding species relationships. We have been analyzing worldwide phylogenetic patterns of sicariid species and their venoms, but I will focus this talk on patterns specific to North American Loxosceles and South American members of the Loxosceles laeta species group. Methods: We isolated and sequenced venom expressed SMase D cDNAs from multiple species of Loxosceles from North America (Loxosceles reclusa species group) and the L. laeta species group. We analyzed phylogenetic relationships among these genes and compared them with patterns of relationships of species as inferred from $28 \mathrm{~s}, \mathrm{CO} 1,16 \mathrm{~s}$, and ND1 sequence data. We also analyzed the SMase D genes to infer which parts of the protein are evolving under positive selection and perhaps involved in evolution of functional specificity.

Results: Species relationships of Loxosceles indicate that this genus colonized southern North America from South America and has been present on North America for at least 33 million years. Multiple lineages migrated northward leading to at least two lineages in the USA that are more closely related to species in Mexico than they are to other US species. While some SMase D genes of closely related species are more similar to one another than they are to distantly related species, frequent duplications add complexity to patterns of similarity of expressed SicTox genes in venoms. From Loxosceles arizonica alone we have isolated genes that are from five independent SicTox lineages. The South American L. laeta species group is interesting in that their SMase D genes are more different from those of other New World species than would be expected based on 
species relationships. While our sampling is not yet thorough enough to infer the timing of the evolutionary change that led to divergence of these proteins, we have found that the divergent genes are present in a broad range of species in the L. laeta species group.

\section{THE IMPRACTICALITY OF GOOD MEDICAL CARE: FOREIGN ANTIVENOM USE IN THE UNITED STATES}

Boyer $\mathrm{LV}^{(1,2)}$, Shirazi $\mathrm{F}^{(1,3)}$, Degan $\mathrm{J}^{(1)}$.

1. VIPER Institute

2. Department of Pathology

3. Department of Emergency Medicine, University of Arizona, Tucson, AZ, USA

boyer@pharmacy.arizona.edu

Background: One antivenom in the USA is licensed for use in rattlesnake envenomations. Other antivenoms that may be effective exist and are kept in zoos or in other countries. Use of these products is subject to their emergency availability and to the use of the Investigational New Drug (IND) mechanism.

Case Report: A child was bitten by a rattlesnake. He developed severe envenomation, including coagulopathy. Treatment with CroFab was complicated by anaphylaxis. Coagulation abnormalities, accompanied by bleeding, continued, provoking a debate about the cost/benefit analysis of using more antivenom. Several attempts at management of anaphylaxis and reinitiation of treatment were made, but respiratory distress prevented this, and bleeding continued. Inquiries were made to multiple sources of alternative treatments, including the nearest zoos and foreign pharmacies. Antivenom was requested from three sources, for urgent delivery to the intensive care unit late on a Friday night. Additional calls went to the regional poison control center, to the US FDA, to several airline companies, and to health care professionals in four Arizona and Sonora towns. Transport required four cars, one helicopter, one commercial jet, and one motorcycle belonging to a passer-by in a border traffic jam. Human subject protection involved the efforts of medical specialists, research staff, FDA employees, two IRBs, social workers, and a judge, for permission to use an investigational drug in a ward of the state. Cost of antivenom, for which there was no patient billing mechanism, was borne in part by a Mexican physician and by the donating zoo. The patient received two different foreign products, without evidence of hypersensitivity. Coagulation abnormalities were corrected and bleeding ceased shortly after treatment.

Discussion: This happened under best-case circumstances, with toxicologists who were experienced in treatment of snakebite, regulatory compliance, zoo antivenom acquisition, and IRB interaction. As happens with emergency use of antivenom for exotic snakebites, we had no established protocol or mechanism for pooling data toward improved future understanding of the disease and its treatment. Although patient care had a satisfactory outcome, we imposed emergency workload and costs unfairly on individuals and organizations that should not be responsible for US medical care.

Conclusion: We have no system to assure the safe use and efficient delivery of most types of antivenom to US snakebite patients. We need one.

\section{SUBACUTE COAGULOPATHY IN SNAKE ENVENOMATION: A RANDOMIZED, COMPARATIVE TRIAL OF FAB AND F(AB' $)_{2}$ ANTIVENOMS IN ARIZONA}

Boyer $\mathrm{LV}^{(1)}$, Alagon $\mathrm{A}^{(2)}$.

1. College of Medicine, University of Arizona, Tucson, AZ USA

2. Instituto de Biotecnología, UNAM, Cuernavaca, Mexico boyer@pharmacy.arizona.edu

Background: Envenomation by pit vipers is associated with coagulation disorders including hypofibrinogenemia and thrombocytopenia. Correction of these abnormalities during the acute phase of the disease has been described with whole $\left.\operatorname{IgG}, \mathrm{F}(\mathrm{ab})_{2}\right)_{2}$, and Fab antivenoms. Delayed or recurrent coagulation abnormalities have been reported in the subacute phase following use of Fab antivenom, resulting in risk of hemorrhage or death. We hypothesized that longer plasma persistence of $\mathrm{F}\left(\mathrm{ab}^{\prime}\right)_{2}$ antivenom in patients at risk of coagulopathy would result in decreased coagulopathy 1 week after treatment.

Methods: This was a phase 2, randomized comparative clinical trial of snakebitten adults presenting for care in Tucson, AZ, USA. Patients received either Fab (CroFab) or $\mathrm{F}\left(\mathrm{ab} \mathrm{b}_{2}\right)_{2}$ (Antivipmyn) antivenom using a predefined treatment schedule. Endpoints included platelet counts, fibrinogen levels, and venom and antivenom ELISAs. Measurements were conducted at baseline and at various times over the following 2 weeks.

Results: Twelve patients were studied, with six randomly assigned to each treatment group. Response of platelet counts, fibrinogen, and venom levels to acute treatment was similar in the two groups. One week following treatment, platelet counts and fibrinogen levels were lower in the Fab group than in the $F\left(a b^{\prime}\right)_{2}$ group, following a characteristic pattern that reached its lowest point approximately 1 week after initial treatment. Venom levels dropped below detection limits in all patients following initial treatment, but subsequently rebounded into the measurable range in four of six Fab cases. $F\left(a b^{\prime}\right)_{2}$ antivenom levels demonstrated a longer 
plasma persistence than Fab levels, with a less rapid drop during the 2 days following treatment. Two patients in the Fab group had significant adverse events involving coagulation abnormalities, for which additional antivenom was administered following the initial treatment period.

Conclusions: Following the acute phase of presentation and treatment for envenomation, there appears to be a roughly 2-week subacute phase of the disease during which ongoing presence of venom may result in serious delayed or recurrent coagulation defects. Late hypofibrinogenemia and thrombocytopenia are associated with recurrent venonemia and drop in antivenom levels. This pattern was apparent in patients treated with Fab antivenom but was not seen among $F\left(a b^{\prime}\right)_{2}$ recipients in this phase 2 study, consistent with pharmacokinetic differences between the two products.

\section{SCORPION ENVENOMATION IN ARIZONA: STATUS 10 YEARS AFTER CESSATION OF U.S. SCORPION ANTIVENOM PRODUCTION}

Boyer L.

Department of Pathology and VIPER Institute, University of Arizona, Tucson, AZ, USA

boyer@pharmacy.arizona.edu

Background: Annually, over 200 Arizonans experience scorpion neurotoxicity of sufficient severity to warrant intensive care. Antivenom against scorpion venom was produced in Arizona until 1999, and the last vial outdated in 2004. Clinical trials of a potential replacement product (Anascorp ${ }^{\circledR}$, Centruroides [scorpion] immune $\mathrm{F}(\mathrm{ab})_{2}$ intravenous [equine]) began in 2004. This antivenom, previously licensed in Mexico, is an investigational product in the USA. Methods: We conducted a double-blind, placebo-controlled trial of scorpion antivenom in critically ill children; openlabel clinical trials of antivenom in children and in adults; an open-label treatment protocol study; one video education study; one pharmacoeconomic study; and one historical controls study. Endpoints included syndrome resolution by $4 \mathrm{~h}$ after treatment, cumulative midazolam dose, plasma venom levels, and overall cost of care.

Results: Over 6 years, 933 scorpion-stung patients were studied, including seven placebo recipients and 97 historical controls in six linked clinical studies. Use of the study antivenom was associated with faster resolution of neurotoxicity, lower dosing of concomitant midazolam sedation, faster resolution of venom antigenemia, and lower cost of care than treatment without antivenom.

Discussion: It is expensive, difficult, and time-consuming, but with protocols adapted to a variety of healthcare settings, it is possible to make a robust demonstration of clinical efficacy and safety of antivenom. The product we studied appears to be safe and effective for the rapid reversal of scorpion neurotoxicity. More efficient methods must be developed and agreed upon, perhaps relying more heavily on animal models and/or surrogate markers, if the USA is to help address the worldwide antivenom shortage. Favorable pharmacoeconomic findings in this unusually thoroughly documented setting support the expectation that international collaboration may be cost-effective as well as medically beneficial.

Conclusion: A decade after cessation of production of the prior standard, Arizona has accumulated a sufficient mass of data to make the clinical case for approval of an $F\left(a b^{\prime}\right)_{2}$ scorpion antivenom.

\section{A 60 YEAR-OLD MALE WITH HEMOCONCENTRA- TION, BLOODY DIARRHEA, AND ALTERED MENTAL STATUS SECONDARY TO INTRAVASCULAR CROTALID ENVENOMATION}

Burns BD ${ }^{(1)}$, Banner $\mathrm{W}^{(2)}$

1. Oklahoma University School of Community Medicine, Tulsa, OK, USA

2. University of Oklahoma Health Science Center, Oklahoma Poison Center, Oklahoma City, OK, USA

boyd-burns@ouhsc.edu

Background: Each year, in the USA pit vipers are responsible for the majority of all snake bites. The overall mortality remains low, except in the case of intravascular envenomation. This rare case demonstrates the severity and the rapidity in which the symptoms develop and the organ systems involved. Hemoconcentration has been demonstrated in the animal and described in humans with direct venom injections intravenously.

Case Report: A 60-year-old male presented to our Emergency Department approximately $2 \mathrm{~h}$ after an intravascular envenomation from snakebite to the area of the left ankle. Bystanders report that, within $1 \mathrm{~min}$ of the bite, the patient fell to the ground and was noted to have a significant change in his mental status with vomiting. An adult dose EpiPen was given on scene by family members because the patient was incoherent and unable to communicate, and they were concerned about the possibility of an allergic reaction.

Results: On arrival, he was profoundly confused and hypotensive with bloody diarrhea and evidence of a DIClike coagulopathy and multi-organ dysfunction including renal insufficiency, non-ST elevation myocardial infarction, lactic acidosis, and severe hemoconcentration (Hct 68.7). His only cutaneous sign of envenomation was a small (1$2 \mathrm{~cm}$ ) area of ecchymosis on the lateral aspect of the ankle. 
There was no edema, erythema, bulla, or petechia. He was given aggressive crystalloid resuscitation for circulatory support and received 20 vials of CroFab (ten vials $2 \mathrm{~h}$ apart) and two units of FFP in the Emergency Department. The patient was admitted to the ICU and received another ten vials of CroFab the next hospital day, and ultimately had resolution of his coagulopathy and was discharged on hospital day 5 .

Discussion: Reports of a very small number of patients have been published with suspected intravascular rattlesnake envenomation and mortality for this subset of patients is high even with antivenom.

Conclusion: Patients presenting with hemoconcentration who develop severe symptoms of multi-organ dysfunction, hypotension, and coma require antivenom and aggressive fluid support and antivenom treatment should not be based on cutaneous findings alone.

\section{STILETTO SNAKE (ATRACTASPIS BIBRONII) ENVENOMING}

Bush SP.

Loma Linda University School of Medicine, Medical Center \& Children's Hospital CA, USA

sbush@llu.edu

Background: Snakes from the family Atractaspididae have varying clinical importance and are considered distinct from the Viperidae, Colubridae, Elapidae, etc. This can lead to interesting therapeutic and legal implications. Atractaspis bibronii is commonly known as a stiletto snake, mole viper, or Bibron's burrowing asp. Generally, A. bibronii is found in southern Africa but can also turn up in private collections due to possible loopholes in state laws. Because of their dagger-like, side-stabbing fangs, these snakes are difficult if not impossible to manually hold. Among other things, $A$. bibronii venom contains sarafotoxins and metalloproteases, which may lead to the expected effects of hypertension, pain, and local necrosis.

Case report: A 24-year-old patient presented to a southern California Emergency Department 2 days after a bite by $A$. bibronii. There was no specific antivenom readily available in southern California for envenoming by this snake. Available antivenoms included Crotalidae Polyvalent Immune Fab Ovine, SAIMR Polyvalent Antivenom, and possibly others. However, antivenoms developed against venoms of snakes from other families would likely have little or no cross-protectivity because of the distance of phylogenetic relationships. A new antivenom has been developed against Atractaspis species in other parts of Africa; however, this antivenom was not available to the treating physicians and its efficacy against $A$. bibronii is unknown. When the risks, benefits, and alternatives were explained to the patient, he elected not to receive any of the available antivenoms. Approximately 3 weeks after the bite, he patient suffered auto-amputation of the thumb at the interphalangeal joint. Subsequently, he was grafted with a partially functional and favorable cosmetic outcome.

\section{WHAT THE HELLERI IS GOING ON IN SOUTHERN CALIFORNIA? THROMBOTIC STROKES FOLLOWING CROFAB-TREATED SOUTHERN PACIFIC RATTLESNAKE (CROTALUS OREGANUS HELLERI) ENVENOMING}

Bush SP.

Loma Linda University School of Medicine, Medical Center \& Children's Hospital, CA, USA

sbush@llu.edu

A 17-year-old male patient was bitten on the ring finger at 1840 on $6 / 28 / 08$ by a southern Pacific rattlesnake (dead specimen recovered and identified by the author). He had progressive pain and swelling up his entire arm into the chest wall but was improving after 28 vials of CroFab. He also had a mild coagulopathy, which had almost completely normalized. However, at 1940 on 7/1/08, $97 \mathrm{~h}$ after the bite, he suddenly developed left facial and left upper extremity greater than left lower extremity weakness. Speech was normal, but he had difficulty walking. A head CT scan showed no intracranial bleed. MRI on 7/2/08 showed an acute infarction in the distribution of the right middle cerebral artery as well as other tiny scattered foci of acute infarctions in the bilateral frontal and occipital lobes and in the right cerebellar hemisphere. Over the next few days, the patient started to have coagulopathy recurrence. However, because of the concern that the strokes may have resulted from an interaction between the antivenom and southern Pacific rattlesnake venom in this particular individual, additional CroFab was withheld unless published guidelines were reached (e.g., INR greater than 3). On 7/9/08, 8 days after the stroke, there was not much in terms of neurological improvement, but his neurological status did not worsen and, at this point, he was walking with physical therapy. He was still not able to use his left arm much at all. His thrombocytopenia recurrence bottomed-out at 45 and then trended upward to eventually normalize. No more antivenom (of any kind) was given after the stroke. Special laboratory testing all returned normal, including thrombin time, protein $\mathrm{C}$, lupus anticoagulant test, and others to be presented. There have been studies showing that CroFab did not protect mice against lethality associated with southern Pacific rattlesnake envenoming. Mixed results using $\mathrm{CroFab}$ for this particular species have been observed 
at this Medical Center. A similar but fatal presentation has been observed before in a 52 -year-old male.

\section{VIPER BITES IN AFRICA: EPIDEMIOLOGY AND MANAGEMENT}

\author{
Chippaux JP. \\ Institut de Recherche pour le Développement, Paris, France \\ jean-philippe.chippaux@ird.fr
}

Background: In sub-Saharan Africa, most of the envenomations are consecutive to viper bite. While in forest, different kinds of vipers (Bitis, Atheris, and Causus) may be involved; in savannas, bites are mostly due to Echis species. In rural areas, incidence may be very high and regards mainly young men bitten during farming. More than 500,000 viper envenomations leading to 20,000 deaths occur in sub-Saharan Africa each year.

Clinical syndrome: Viper bites induce inflammatory syndrome (extensive edema) in $85 \%$ of the patients, coagulation disorders (permanent local bleeding for over an hour, ecchymosis, blisters, and hemorrhages) in $40 \%$, and necrosis in $5 \%$. There are very few observations of neurotoxicity in some Bitis envenomations in South Africa. Severity of envenomation depends on the toxicity and amount of injected venom, the time between the bite and medical treatment, and the management of envenomation, i.e., the accessibility of antivenom and training of health personnel.

Medical care: The delay in medical consultation is due to victim's therapeutic choice and scarcity of health centers. Antivenom shortage results from high cost, poor knowledge on its use (indication, administration route, dosage, etc.), unfounded fear of severe adverse reactions, and poor stock control. As a consequence, the use of antivenom remains under $10 \%$ of the actual needs.

Antivenom: Antivenom treatment of envenomations by hundreds of vipers showed that highly purified $F\left(a b^{\prime}\right)_{2} \operatorname{IgG}$ fragments administered intravenously were effective and well tolerated. More than $95 \%$ of the bleedings are stopped within $12 \mathrm{~h}$ after the antivenom administration and restoration of coagulation was attained within $24 \mathrm{~h}$ in $90 \%$ of the patients. A recent clinical study suggested than the dosage generally used could be reduced without significant consequences for the efficacy of treatment. However, it seems that antivenom treatment does not guarantee a rapid restoration of coagulation factors in all the patients. Although venom seems neutralized by the antivenom, few patients may suffer from persistent coagulation defect and/or relapse, especially if there has been a long delay between bite and treatment. The use of adjuvant treatments seems necessary to substitute for lacking coagulation factors and accelerate the restoration of blood coagulation.

\section{RATTLESNAKE VERSUS AGKISTRODON ENVENOMATIONS: VENOM EFFECTS DIFFERENCES}

Chuang $\mathrm{RC}^{(1,2)}$, Kokko $\mathrm{J}^{(1)}$, Mlynarchek $\mathrm{SL}^{(1)}$, Schaeffer $\mathrm{TH}^{(1,2)}$, Bogdan $\mathrm{GM}^{(1)}$, Lavonas $\mathrm{EJ}^{(1,2)}$.

1. Rocky Mountain Poison \& Drug Center, Denver Health, Denver, $C O$

2. University of Colorado Denver School of Medicine, Aurora, $\mathrm{CO}$

ryan.chuang@rmpdc.org

Introduction: Although rattlesnake (genera Crotalus and Sistrurus) envenomations are generally considered to be more severe than copperhead and cottonmouth snake (Agkistrodon contortrix and Agkistrodon piscivorus) envenomations, little direct evidence supports this assumption.

Methods: We analyzed data from a multicenter retrospective cohort study of patients treated with crotalinae Fab antivenom (2002-2004). Observations about initial severity, specific venom effects, Fab antivenom dose, and response to therapy were compared between snake genera and species. Investigators from 17 sites abstracted data to a standardized form. Data for each Crotalus and Sistrurus species and "unknown rattlesnake" were pooled into one group and data for the Agkistrodon species were pooled into another for our main analyses. Analyses were also performed on the separate snake species. Descriptive statistics and Fisher's exact tests were used.

Results: Two hundred forty-seven patient records were reviewed. After excluding unknown species envenomations, 144 cases were available for analysis. Prior to antivenom, rattlesnake envenomations were more severe than Agkistrodon envenomations. Rattlesnake victims were more likely to have coagulopathy $[24 / 80(30 \%)$ vs. $5 / 56$ $(10 \%)(p=0.003)]$, thrombocytopenia [15/81 (19\%) vs. $2 / 52$ $(4 \%)(p=0.02)]$, cardiovascular effects [22/86 (26\%) vs. 5/ $58(9 \%)(p=0.02)]$, and neurotoxicity $42 / 86[(49 \%)$ vs. $6 / 58$ $(10 \%)(p<0.001)]$. Initial control of the envenomation syndrome was achieved in 65/86 (76\%) of rattlesnake envenomations and 54/58 (93\%) of Agkistrodon cases ( $p=$ 0.02). Although the median number of antivenom vials used to achieve initial control was similar (6 vs. 5 vials), $11 / 65(17 \%)$ of rattlesnake victims and $1 / 54(2 \%)$ of Agkistrodon victims required more than 12 vials to achieve initial control $(p=0.006)$. Species-specific analyses showed that $A$. piscivorus envenomations tended to have more clinical effects compared with $A$. contortrix, whereas Sistrurus miliarius envenomations appeared less severe than Crotalus species envenomations. However, since there were only a small number of $A$. piscivorus and $S$. miliarius envenomations, these observations should be interpreted with caution. 
Conclusion: Rattlesnake envenomations tend to be more severe than Agkistrodon envenomations because of hematologic, cardiovascular, and neurotoxic effects and were more likely to require large antivenom doses for initial control.

\section{RAPID-ONSET SHOCK AND/OR ANAPHYLACTOID REACTIONS FROM RATTLESNAKE BITES IN CENTRAL ARIZONA}

Curry SC, O'Connor AD, Ruha AM.

Dept. of Medical Toxicology and Banner Good Samaritan Poison Center, Banner Good Samaritan Medical Center, Phoenix, AZ, USA

steven.curry@bannerhealth.com

Background: Beginning about 2003, an increasing frequency of rattlesnake bite (RSB) patients with refractory hypotension/shock/collapse, CNS depression, and/or oralfacial edema was recognized in our practice. Previously, these patients were encountered approximately once every 2 years.

Methods: Medical practice records of RSB patients cared for by a group of medical toxicologists between 1 July 2004 and 30 June 2008 were reviewed to identify patients with $\mathrm{SBP}<90 \mathrm{mmHg}$ within $30 \mathrm{~min}$ of the bite, airway swelling, and/or lethargy/coma/collapse $<30 \mathrm{~min}$ post-bite. Data were collected, excluding identifying information that would allow patient identification (IRB not applicable).

Results: Fifteen of 209 RSB patients fulfilled the above criteria. Fourteen of fifteen suffered rapid onset of hypotension, and 11/14 required vasopressors, usually epinephrine, despite large fluid challenges. Eight of fifteen experienced objective or subjective airway edema; 5/ 8 required endotracheal intubation. Morbidity accompanying shock and edema, sometimes in the face of hematologic effects of venom, are notable for: 7/15 had large to massive GI bleeds; 5/15 developed acute renal failure; 5/15 experienced collapse, coma or obtundation; $3 /$ 15 had systemic rhabdomyolysis; one suffered multiple strokes, and one died with ARDS. Ischemic colitis appeared frequently. Two patients suffered previous RSB, and three additional patients had experienced skin contact with rattlesnakes. Ages ranged from 7 to 57 years and the geographic locations of the bites fit no pattern. Snakes were identified in 3/15 instances: two were Crotalus scutulatus and one was Crotalus cerastes.

Discussion: IgE-mediated anaphylactic reactions or intravascular envenomations do not provide a plausible explanation for the syndrome in the majority of our patients. Rather, an anaphylactoid response to venom appears most likely. Bradykinin-potentiating peptides and C-natriuretic peptides in venom produce vasodilation, capillary leak, hemoconcentration, hypotension, degranulation of mast cells, and angioedema, and these could be the primary venom components responsible for the constellation of findings in these patients apart from typical venom effects on platelets and coagulation. The explanation for the increased rate of such patients seen in central Arizona is not explained by increased total RSB patients, patient age, geographic location of bite, or medication. A chance occurrence seems most likely, though the pattern continued through 2008.

Conclusion: An increased frequency of RSB patients presenting with rapid collapse, early onset shock, and/or airway edema with frequent and severe accompanying morbidity were recognized in central Arizona. An anaphylactoid reaction to venom components provides the most plausible explanation for this syndrome.

\section{A NATIONAL SERUM DEPOT IN THE NETHERLANDS}

Dijkman $\mathrm{MA}^{(1)}$, Van der Zwan $\mathrm{CW}^{(2)}$, Vries de $\mathrm{I}^{(1,3)}$, Meulenbelt $\mathrm{J}^{(1,3,4)}$.

1. National Poisons Information Centre, National Institute for Public Health and the Environment, Bilthoven, The Netherlands

2. National Vaccine Institute, Bilthoven, The Netherlands

3. University Medical Center, Utrecht, The Netherlands

4. Institute for Risk Assessment Sciences, University Utrecht, Utrecht, The Netherlands

Marieke.dijkman@rivm.nl

Introduction: In The Netherlands, keeping venomous animals like snakes, scorpions, and spiders as pets is allowed as long as the animals are kept in a non-dangerous manner. Still, every year, people are bitten or stung by these animals, and some develop signs of envenomation for which antivenom treatment is indicated. Until recently, antivenoms were not or sparely available and supplied by national and international zoos. Given the increasing number of venomous snakebite incidents with possible severe clinical outcome, zoos became reluctant delivering antivenom because they are not obliged, and it is not their wish to provide them. They demanded for a national serum depot. The Ministry of Health, Welfare and Sports decided to establish a national serum depot, guaranteeing rapid antivenom supply during medical emergencies.

Results: The national serum depot is a cooperation between two government-owned companies. The Netherlands Vaccine Institute is responsible for purchasing, storage, and distribution, and the National Poisons Information Centre (PIC) for recommendations concerning the content of the depot and antivenom treatment indications. To determine the antivenoms needed for the national Serum depot, the 
following assumptions were made. First, almost every venomous animal that can induce a potential life-threatening envenomation is kept in The Netherlands. In relation to venomous snakes, this was confirmed to be correct by a herpetological society. Second, enough antivenom to treat at least one patient should be available. Based upon information from antivenom producers, available in medical literature and on internet, the average amount of ampoules to be used was determined. If this was not known, the starting dose and two repeating dosages were advised. If several antivenoms were available for one animal species, the choice was made on basis of safety and efficacy information. Good contact with professional herpetologists has resulted in valuable adjustments to the original contents of the depot. Approximately 50.000 euro per year is available for antivenoms and all administrative and storage processes involved with this. If there is an envenomation, the treating physician contacts the PIC for information concerning possible signs and symptoms and antivenom treatment indications. If antivenom treatment is necessary, the PIC informs the Netherlands Vaccine Institute who will distribute the antivenom immediately to the pharmacy of the hospital were the patient is treated.

Conclusions: Since spring 2008, a national serum depot is operational.

\section{THE EVOLUTION AND DIVERSIFICATION OF THE REPTILE VENOM SYSTEM}

Fry BG.

Department of Biochemistry \& Molecular Biology, Bio21 Institute, University of Melbourne, Melbourne, Victoria, Australia

bgf@unimelb.edu.au

Background: The reptile venom system has been an area of long-standing interest and considerable conjecture, with some areas being particularly neglected, such as the predatory ecology of Varanus komodoensis (Komodo Dragon).

Methods: We investigated the roles and potential interplay between cranial mechanics, toxic bacteria and venom in $V$. komodoensis.

Results: Our analyses pointed to the presence of a sophisticated combined-arsenal killing apparatus. We found that the lightweight skull was relatively poorly adapted to generate high bite forces, but better adapted to resist high pulling loads.

Discussion: We rejected the popular notion regarding toxic bacteria utilisation. Instead, we demonstrated that the effects of deep wounds inflicted are potentiated through venom with toxic activities including anticoagulation and shock induction. Anatomical comparisons of $V$. komodoensis with Varanus (Megalania) prisca fossils suggested that the closely related extinct giant was the largest venomous animal to have lived. These results are placed in their relative position within the larger picture through comparisons not only with other extant venomous lizards such as the gila monster but also in relation to the venomous snakes. This allowed for generalised statements to be made regarding the evolutionary selection pressures driving the changes in this integrated weapons system.

\section{USE OF PHYSICAL THERAPY IN SUCCESSFUL RECOVERY AFTER SNAKEBITE}

Harrison JR, Wiley KL

Kentucky Reptile Zoo, Slade, KY, USA

reptilezoo@bellsouth.net

Introduction: Disability as a result of snakebite is a problem that has had limited attention. Disability is greatly minimized with appropriate physical therapy; however, many PT practitioners have limited or no experience with snakebite victims. The goal of recovery after any traumatic injury is for the victim to be able to return to normal life activities and not be hindered by after-effects of the injury. Methods: In this paper, we discuss physical therapy techniques and limits that have been effective in treating our own snakebites.

Results: After appropriate rehabilitation, we have been successful in returning to work and play after snakebites.

Discussion: Bites that result in necrosis must be handled differently than bites that do not involve necrosis at the bite site. For bites without necrosis, stretching, massage, and basic movements can be achieved almost immediately (24$48 \mathrm{~h}$ ) after the bite. This can reduce tendonitis and keep scar tissue flexible as it forms. For bites with necrosis, we have had success with a technique that combines hot soaking, movement, and dry bandaging. Caution must be used when treating cases involving potential gangrene. Duration of physical therapy may be quite long, lasting months or even up to a year, but near $100 \%$ recovery has been seen even with quite severe tissue damage.

\section{MY LIFE AS A SNAKEBITE VICTIM}

Harrison JR, Wiley KL.

Kentucky Reptile Zoo, Slade, KY, USA

reptilezoo@bellsouth.net

Introduction: A single patient has been bitten a number of times by a variety of snake species over his career as a venomous animal keeper. 
Discussion: Medical and logistical problems occurred with several different bites. Pre-bite planning and protocol use has been used to prevent or limit such problems in the future. A number of common issues typically occur with these bites: communication difficulties between patient and physician, especially when the patient is a herper; protocol use and development; antivenin use, especially the use of foreign antivenins in the USA; and speed of progression of the bite symptoms and the element of surprise.

Conclusions: Experience with past problems can aid physicians and potential victims in preventing complications in the future.

\section{DOGS AND CATS WITH SCORPION STINGS}

Holzman SD, Reilly LA, McNally JT, Boyer LV. Arizona Poison and Drug Information Center, Tucson, AZ, USA

holzman@pharmacy.arizona.edu

Background: In 2008, the Arizona Poison and Drug Information Center managed 2,365 scorpion stings in humans and 38 scorpion stings in animals. Although our center has guidelines for treatment of scorpion stings in humans, we do not have information on what signs to expect or how to manage scorpion stings in dogs and cats. Methods: From January 2007 through December 2008, callers whose dogs or cats had been stung by a scorpion were asked to participate in a study to learn about the type of signs their pets experienced and the length of time the signs lasted. Signs recorded were spontaneously reported by the pet owners. Signs were categorized as "syndrome" (tremors, nystagmus, respiratory changes, gastrointestinal, restlessness, and drooling), "non-syndrome" (limping, yelping, pawing, rubbing, licking, shaking head, drowsiness, jumped, sneezing, and others), and "local" (limping, pawing, rubbing, licking, shaking head, and jumped).

Results: Of 84 pet cases collected during the study period, 72 responded to follow-up calls for study completion. Dog weight varied from 2 to $215 \mathrm{lb}$. Cat weight varied from 3 to $16 \mathrm{lb}$. Signs described by category are listed in the table. The average symptom duration was $8 \mathrm{~h}$, (range, $1-120 \mathrm{~h}$ ).

Discussion: Some pets exhibited systemic signs similar to those reported in children stung by bark scorpions. The local signs indicate some level of discomfort, perhaps analogous to the symptoms of paresthesias and pain reported in humans. Veterinary management protocols should reflect the greater vulnerability of animals weighing less than $33 \mathrm{lb}$, particularly cats.

Conclusion: The majority of pets do not show systemic signs following a sting. However, among small animals, a substantial number may need close observation or veteri- nary care. More information on the differences between the signs observed in dogs and cats may be helpful.

\begin{tabular}{lllll}
\hline & Syndrome & $\begin{array}{l}\text { Non- } \\
\text { syndrome }\end{array}$ & Local & $\begin{array}{l}\text { Duration } \\
<4 \mathrm{~h}\end{array}$ \\
\hline Cat $(n=7)$ & $5(71 \%)$ & $7(100 \%)$ & $4(57 \%)$ & $2(29 \%)$ \\
$\begin{array}{c}\text { Dog, small, } \\
<33 \mathrm{lb}(n=41)\end{array}$ & $16(39 \%)$ & $37(90 \%)$ & $33(80 \%)$ & $25(61 \%)$ \\
$\begin{array}{c}\text { Dog, large, } \\
>33 \mathrm{lb}(n=24)\end{array}$ & $3(13 \%)$ & $21(88 \%)$ & $16(67 \%)$ & $17(71 \%)$ \\
\hline
\end{tabular}

\section{COLUBRID VENOMS: PHARMACOLOGY VS. BIOLOGICAL ROLE}

\author{
Kardong KV. \\ School of Biological Sciences, Washington State University, \\ Pullman, WA, USA \\ kkardong@wsu.edu
}

Background: Pharmacologists and evolutionary biologists may occasionally work at cross-purposes when examining squamate oral secretions as, understandably, one group focuses on health risks and the other on evolving form/ function roles of oral secretions, respectively. This division is particularly evident with work on snakes referenced to the convenient, but paraphyletic group, colubrids.

Methods: Comparative anatomical, functional, and adaptive analysis of oral glands in squamates.

Results: True venom systems evolved in only two living groups of reptiles - early in helodermatid lizards and late in advanced snakes (atractaspids, vipers, pit vipers, cobras, and allies). The venom system of advanced snakes is a closed system producing the discharge of a venom bolus from a glandular reservoir under high pressure. Colubrid snakes lack such a system but about one quarter of the species possess a Duvernoy's gland, of great anatomical and chemical diversity, which is a low-pressure, open system. Consequently, predatory systems in such colubrids employ a different adaptive strategy than in truly venomous snakes. Furthermore, Duvernoy's glands and venom systems produce biochemical components that perform multiple biological functions, not just dispatch prey. The failure to elucidate these various biological roles, especially in colubrid snakes, continues to impede clear analysis of evolutionary events within squamates. This has been further complicated and confused by ill-advised calls to brand all members of one squamate clade, from lizards to basal snakes to advanced snakes as "venomous".

Conclusion: Such an expansive use of the term "venomous", even mapped on to a good phylogeny, underestimates the complexity of the chemical, morphological, and 
behavioral events that come together into a true venom system. This expansive use of "venomous" should be discouraged because it implies an overall danger that does not exist, misleads in the assessment of medical risks, and obscures the complexity of evolutionary events that contribute to the late development of a snake venom system.

\section{SIGNIFICANT LOCAL ENVENOMING BY THE WESTERN HOGNOSE SNAKE (HETERODON NASICUS): A CASE REPORT}

\author{
Keyler $\mathrm{DE}^{(1,2)}$, Weinstein $\mathrm{SA}^{(3,4)}$. \\ 1. Toxicology, Minneapolis Medical Research Foundation \\ 2. Dept. of Experimental \& Clinical Pharmacology Univer- \\ sity of Minnesota, Minneapolis, MN, USA \\ 3. Dept. of Clinical Toxinology, Women's and Children's \\ Hospital \\ 4. Royal Adelaide Hospital, Internal Medicine Service, \\ Adelaide, South Australia \\ keyle001@umn.edu
}

Background: Bites to humans by the colubrid, Heterodon nasicus, have been reported to cause adverse effects. Often, details of the symptoms are poorly documented; some clinical symptoms mimic those observed in early stages of viperid envenoming, and controversy exists concerning the legitimacy of observed and reported clinical complications. The present case describes a clinically significant local envenoming that resulted from a bite inflicted by a Western hognose snake, H. nasicus.

Case Report: A 21-year-old female was bitten while offering a juvenile mouse to a captive snake that was maintained in a rural university collection. The snake maintained a grip on the patient's arm (left anticubital fossa) for 3-5 min. After $3 \mathrm{~h}$, marked swelling developed, and the patient sought medical attention. Due to the physician's inexperience with treating snakebite and having no knowledge of venomous snakes, air transport was requested to a level 1-trauma center. No consultation with university professors or outside toxicology consultation was requested prior to transport. In the $\mathrm{ED}$, approximately $5 \mathrm{~h}$ after the bite, marked edema, ecchymoses, lymphadenopathy, and cutaneous signs suggestive of mild cellulitis and bleb formation were observed. The patient was admitted for overnight observation; no systemic effects were observed, but local complications were persistent, and recovery was not complete until approximately 5 months.

Discussion: This case confirms that $H$. nasicus bites to humans can result in significant local complications that may not rapidly resolve. It is currently unclear whether the pathological changes associated with these bites are due to specific Duvernoy's secretion components, type I hypersensitivity, or a combination of these. Furthermore, it illustrates the confusion and uncertainty with medical professionals, based on observed local symptoms, as to an appropriate course of action following a snakebite from a relatively non-venomous species.

Conclusion: This common xenodontine colubrid is considered capable of inflicting medically significant bites. However, H. nasicus bites should not be considered dangerous. Captive specimens should be handled carefully, particularly when offered food. Medical personnel unfamiliar with treating snakebite should seek toxicology consultation prior to taking any major course of action.

\section{CAPTIVE COBRA (NAJA SP.) CASES IN NORTH AMERICA (1984-2009)}

Keyler DE.

Toxicology, Minneapolis Medical Research Foundation and Dept. Experimental and Clinical Pharmacology, University of Minnesota, Minneapolis, MN, USA

keyle001@umn.edu

Background: Non-native venomous snakes, especially cobras, have become increasingly prevalent in amateur herpetologist collections in North America. When amateurs are bitten, they present to emergency department staff who usually have a limited knowledge of what to anticipate clinically or what potential treatments may be useful. The significant features resulting from captive cobra bites in North America, such as cobra venom-induced medical complications, time-course of major complications, basic supportive measures applied, antivenoms administered, and final outcomes are reviewed.

Methods: Cobra bite cases were extracted from a database of 190 venomous snakebite consultations from 1984-2009. Consultations were requested, at various time points following envenomation, from emergency departments or actual snakebite victims directly. Respiratory complications, local venom effects, treatments, including antivenom use, and outcomes were documented.

Results: Of the 35 non-native venomous snakebites consulted on, 13 (37\%) resulted from bites by six different cobra species. Naja kaouthia was the species most commonly responsible (six cases, $46 \%$ ). Bites occurred in nine different states in the USA and one province in Canada. Cobras were from private collections, and snakebite victims were amateur herpetologists. Respiratory support was required in five (38\%) patients, while two others exhibited lesser respiratory distress. Ventilation support time ranged from $8-72 \mathrm{~h}$. Seven $(54 \%)$ patients were treated with antivenom, and time to treatment ranged from $2-7 \mathrm{~h}$. In three cases, non-specific antivenoms $(N$. 
kaouthia/SA Poly; $N$. kaouthia/CSL Tiger, and $N . n . n a j a / S A$ Poly) were used, and in three cases, the administration of South African Polyvalent AV was discontinued due to allergic complications. Three patients had surgical intervention for local complications, and three patients had ETOH levels $>0.25 \mathrm{mg} / \mathrm{dl}$.There were no fatalities.

Conclusions: Naja (cobras) continues to be a common genus of non-native venomous snakes involved in cases of envenomation to amateurs in North America. Respiratory failure requiring intubation prior to antivenom administration is frequent since time to treatment is delayed, and appropriate antivenoms are often not readily available. Ventilator support may be of sustained duration despite antivenom therapy. Non-specific antivenom effectiveness in providing para-specific coverage for Asian cobra species is of questionable efficacy. In addition to respiratory compromise, concurrent severe wound complications should be anticipated even when antivenom has been administered.

\section{A VENOMOUS HUSBANDRY AND MANAGEMENT COURSE FOR U.S. FACILITIES}

Krebs, $\mathrm{J}^{(1)}$, Hahn, $\mathrm{R}^{(2)}$.

1. Omaha's Henry Doorly Zoo Omaha, NE, USA

2. Catoctin Wildlife Preserve and Zoo, Thurmont, MD, USA jkrebs@omahazoo.com

Background: Training for the handling of venomous reptiles in US zoos has traditionally been done utilizing a one-on-one method with no standardization between institutions. Zoos with no baseline handling experience are left with very few resources to self-educate. The American Association of Zookeepers (AAZK) in conjunction with Catoctin Wildlife Preserve and Zoo, Thurmont, MD, organized the first 2-day venomous husbandry and management course in May of 2008.

Methods: The 2-day course consisted of topics covering many aspects of venomous management including: appropriate primary enclosure and facility design, HVAC considerations, infectious diseases and treatments, special neonatal issues, quarantine procedures, safety procedures and manuals for training new employees, evaluation methods, basic taxonomy and toxicology, nutrition, husbandry, regulations, tools, handling, crisis management, and a practical demonstration lab held at the Wildlife Preserve and Zoo using live specimens from the zoo's collection. Liability concerns by the AAZK limited access to the specimens directly, but handling techniques and new devices such as polyurethane tubing and boxes used as shifts, and medical treatment restraints were demonstrated. Seventeen experienced instructors were used to draft the course curriculum. Fourteen were on hand to conduct the sessions.
Results: Over 27 students from six AZA institutions and the private sector attended the course. The course was also videotaped for distribution and instructor evaluation. At the close of the classroom session, a 30-question test was administered. Initial feedback from the students and instructors was very positive.

Discussion: A training course in the handling of venomous animals for students from AZA institutions has been initiated. Long-term outcomes will be studied, and additional courses are planned.

\section{RATTLESNAKE BITES IN PREGNANT WOMEN}

LaMonica GE, Seifert SA, Rayburn WF.

University of New Mexico School of Medicine, Albuquerque, NM, USA

glamonica@salud.unm.edu

Background: Rattlesnake envenomations cause considerable morbidity and mortality. They occur throughout the continental USA and are especially prevalent in the Southwest. The objectives of this study were to determine the prevalence of such bites in pregnant women and to evaluate any differences in the treatment or outcomes between pregnant and nonpregnant women.

Methods: The database of the American Association of Poison Control Centers was reviewed. Human rattlesnake exposures (coded as "rattlesnake," "Sistrurus," or "Crotalus") between 2001 and 2007 were included. Statistical analysis was by a two-sided Chi-squared test.

Results: Sixty-one poison centers reported a total of 8,413 human rattlesnake exposures, with 767 (9.1\%) involving reproductive-age women ( 15 to 45 years old). Of these, 11 ( $1 \%$ of reproductive-age women and $0.1 \%$ of all bites) were pregnant women ranging from 6 to 37 weeks gestation. All calls were initiated from a healthcare facility. Each patient received intravenous fluids and wound care. Treatment with antivenom $(72.7 \%$ versus $59.9 \%$; $p=0.57)$, overall admission rates $(82 \%$ vs. $54 \%)$, and reports of adverse events to treatment $(0 \%$ vs. $1 \%)$ were not significantly different between pregnant and non-pregnant rattlesnake bite victims, respectively. There were no maternal deaths.

Discussion: Rattlesnake bites to reproductive-age women involve only $9 \%$ of victims, and bites to pregnant women are exceedingly rare. Admission rates and antivenom treatment do not differ between pregnant and non-pregnant patients. Pregnant patients were excluded from the Crotalidae Polyvalent Immune Fab (ovine) Antivenom clinical trials, and there are few case reports in pregnant women. Thus, there is insufficient data to confirm its safety in pregnancy or its efficacy in preventing adverse pregnancy outcomes. Rattlesnake envenomation during pregnancy can cause maternal hypotension, placental abruption, and loss of pregnancy. 
Conclusions: Approximately 110 reproductive-age women are reported to be bitten in the USA each year by rattlesnakes with one or two persons being known to be pregnant. Managements and outcomes appear to be similar to nonpregnant patients in the database of the American Association of Poison Control Centers. In the absence of additional data, treatment should be no different than in non-pregnant women. Prospective studies of snakebite treatment in pregnancy and studies of long-term pregnancy outcomes are necessary.

Table. Gestational age, level of care, outcome code, and antivenom treatment in pregnant rattlesnake bite victims

\begin{tabular}{llll}
\hline $\begin{array}{l}\text { Gestational } \\
\text { age } \\
\text { (weeks) }\end{array}$ & Level of care & Outcome code & Treatment \\
\hline 6 & Noncritical unit & Minor & Yes \\
8 & Noncritical unit & Minor & No \\
15 & Critical unit & Moderate & Yes \\
16 & Treated and & None & No \\
& released & & \\
16 & Critical unit & Major & Yes \\
19 & Critical unit & Moderate & Yes \\
20 & Noncritical unit & Moderate & Yes \\
20 & Critical unit & Minimal & Yes \\
22 & Critical unit & Major & Yes \\
32 & Critical unit & Moderate & Yes \\
37 & Treated and & Minor & No \\
& released & & \\
\hline
\end{tabular}

\section{BITES AND STINGS IN THE WAKE OF STORMS: 1999-2008}

Lewis-Younger CR.

Florida Poison Information Center-Tampa, Tampa, FL, USA

cyounger@tgh.org

Background: Florida's location surrounded by the Atlantic and the Carribean Ocean make the state vulnerable to severe storms, especially hurricanes. The damage that hurricanes pose is related to intensity of the winds, size of the storm, location and direction of landfall, and duration of the hurricane associated rain events. In order to be classified as a hurricane, the storm must have sustained winds of 74 miles per hour. Each storm is unique. Over the past 10 years, data from the National Weather Service indicated that in only 3 years did hurricanes make landfall in Florida: 1999, 2004, and 2005. In 2004, there were four hurricanes that made landfall in Florida and three of those reached category 3 (sustained winds of 111 miles per hour) or higher at the time of landfall. In the years following 2005, Florida has sustained a severe drought, and many ponds and lakes have dried up. Florida is served by a network of three regional poison control centers that share a combined database. Each year, the annual report is calculated and posted to the network web site (www.fpicn.org). This review was undertaken to determine if evidence of a change in the rate of bites and envenomations could be detected during the years that Florida was impacted by storms.

Method: Using population estimates generated by FloridaCharts.com, a rate for reported bites and envenomations for snakes, insects, spiders, and mammals recorded in the Florida statewide reports for 1999-2008 was generated.

Results: The rates for coral snake and all crotaline bites peaked in 2004, the year when four hurricanes hit the state. The rates for mammalian bites increased in both 2004 and 2005, especially for dogs and skunks. Rates for insects and spiders show a different pattern, with rates for bites and stings for many species actually began declining prior to the 2004 and continuing through subsequent drought.

Conclusion: Despite the fact that many cases of exposure are not reported by emergency responders during hurricane events, there does appear to be an increase in bites and envenomations among snakes and mammals in the years with the greatest storm impacts. Envenomations by insects and spiders do not show evidence of increase and may be reflecting other trends, including declines in species numbers.

\section{THE COST-EFFECTIVENESS OF ANTIVENOM TREATMENT IN PEDIATRIC PATIENTS STUNG BY SCORPIONS}

Lowgren $\mathrm{MB}^{(1)}$, Armstrong $\mathrm{EP}^{(1)}$, Boyer $\mathrm{LV}^{(2)}$.

1. College of Pharmacy

2. College of Medicine, University of Arizona, Tucson, Arizona, USA

mbakall@email.arizona.edu

Background: Envenomation by Centruroides scorpions can cause severe symptoms, particularly in children. In the USA, palliative treatment of systemic scorpion envenomation without antivenom commonly requires intensive care. When envenomations occur in rural communities, longdistance transportation to a tertiary care facility is often necessary, by ambulance or helicopter. Antivenom against Centruroides envenomation (Anascorp ${ }^{\circledR}$, Instituto Bioclon SA de CV) is under investigation in Arizona, but effective treatment requires effective product distribution in order to prevent morbidity and costs associated with care in communities that lack intensive care units. This study investigates the cost-effectiveness of antivenom use and also the costeffectiveness of different distribution alternatives.

Methods: We studied the effects on costs and clinical outcomes of three product distribution strategies: no antivenom, 
antivenom available at tertiary centers only, and antivenom available at hospitals in all communities. A decision tree was constructed in TreeAge HealthcarePro. Data on clinical outcomes and resource use was collected from several sources: randomized clinical trials; open label trials; retrospective chart reviews; published literature; and billing departments. Sensitivity analysis was performed using Monte Carlo simulation.

Results: Distribution of antivenom is an important factor in the overall cost-effectiveness of antivenom. Availability of antivenom at tertiary institutions only is more cost-effective than no antivenom. Ready availability of antivenom in all communities reduces frequency of transportation and improves clinical outcomes resulting in an improved cost-effectiveness.

Discussion/Conclusions: Licensure and distribution of scorpion antivenom in Arizona would reduce costs of care currently borne by patients, hospitals, and third-party payers. Decision-tree analysis is a powerful technology that can illustrate the economic dynamics involved in treatment of envenomation in other settings. Adaptation of this model to antivenom distribution and use in other parts of the world that lack sufficient local antivenom supply may facilitate development of improved systems for delivery of patient care.

\section{VARIATION IN VENOM COMPOSITION: SOURCES AND INFLUENCE UPON ENVENOMATION SEQUELAE}

\author{
Mackessy SP. \\ University of Northern Colorado, Greeley, CO, USA \\ stephen.mackessy@unco.edu
}

Introduction: Reptile venoms contain a myriad of potent activities, primarily protein and peptide-based, which severely compromise normal homeostasis when injected into organisms. Furthermore, venom composition varies with several factors, and phylogeny is a major determinant of specific venom constituents. However, even within closely related species, venom composition may vary tremendously, and results of envenomation will also vary significantly.

Methods: Venoms from species representing all major clades of venomous snakes and lizards were extracted and analyzed using enzymology, SDS-PAGE, and MALDITOF-MS; for a limited subset, more detailed proteomic/ genomic analyses and toxicity studies were also conducted. Results for these representative species were then compared with published databases.

Results: Venoms from front-fanged snakes (Elapidae, Viperidae) generally show specific trends in composition, with elapid venoms dominated by numerous smaller mass, specific toxins, whereas viperid venoms are dominated generally by larger mass enzyme toxins, commonly serine and metalloproteases. "Colubrid" venoms generally contain fewer proteins and peptides, but protein mass preponder- ance is more variable than observed with front-fanged snakes. Some species, such as many Boiga, show a high abundance of three-finger and related toxins, which have profound taxon-specific effects (i.e., highly toxic to birds/ lizards, low toxicity to mammals).

Discussion: Because venoms are trophic adaptations which facilitate handling of prey, their effects on different organisms (including humans) are often variable, dependent not only on dose but also on the variant molecules contained in a given venom. Notable exceptions to broad phylogenetic trends occur, and venoms from specific taxa (i.e., US rattlesnakes: Crotalus scutulatus, Crotalus tigris, and Crotalus oreganus concolor; elapids: some Naja and Pseudechis) show very different composition; ensuing effects of envenomation are "atypical" and may be rapidly compromising. Venoms from the rear-fanged snakes ("Colubridae") are generally poorly defined, but most species do not represent a significant health risk. However, highly toxic (to humans) species are known (Dispholidus, Philodryas, Rhabdophis, and Thelotornis), and even for "non-toxic" species, significant effects may be observed if contact (bite) time is prolonged.

Conclusions: The complex sequelae of envenomation depend in large part upon the suite of toxins injected, which in turn is influenced by several factors. Although general trends in symptom development and treatment can be predicted based on the type of offending animal involved, physicians and other health care providers must be aware that very different symptoms may develop depending on the species involved and knowing that a patient was "bitten by a rattlesnake or cobra" is not sufficient for efficacious treatment.

\section{SPECIES IDENTIFICATION, VENOM ANALYSIS, AND THE CLINICAL IMPORTANCE OF AN UNKNOWN CENTRUROIDES COLLECTED IN NEW MEXICO}

Massey $\mathrm{DJ}^{(1)}$, Alagón $\mathrm{A}^{(2)}$, Boyer $\mathrm{LV}^{(3)}$, Franke $\mathrm{OF}^{(4)}$, McNally $\mathrm{JT}^{(1)}$, Sissom $\mathrm{D}^{(5)}$.

1. Arizona Poison and Drug Information Center, Tucson, AZ, USA

2. Instituto de Biotecnología, UNAM, Cuernavaca, Morelos, México

3. VIPER Institute, University of Arizona, Tucson, AZ, USA

4. Instituto de Biología, UNAM, México, DF, México

5. Department of Life, Earth and Environmental Sciences, West Texas A\&M University, Canyon, TX, USA

masseyd@pharmacy.arizona.edu

Background: Centruroides is only one of the many genera of scorpion found within the USA. This genus is distributed throughout the southern half of the USA, from California to 
Florida. Centruroides sculpturatus, located primarily in Arizona, is the only medically important species within this genus. Case report: A child stung by a scorpion while camping at Caballo Lake State Park, NM, presented with neurotoxic symptoms: increased salivation, hyperreflexia, and agitation. The child's grandmother collected the specimen for identification. Tucson clinicians identified the genus of scorpion as Centruroides, but due to atypical patterns compared with local populations of $C$. sculpturatus, along with the incident being east of the documented range of $C$. sculpturatus, the species remained unclear.

Methods: New Mexico Centruroides were collected using UV light at night and locations marked with GPS. Venom samples were obtained with the use of electrical stimulation, collected on Petri dishes, dried at room temperature, and then sealed. Male and female specimens were examined morphologically for identifying characteristics. The New Mexico Centruroides venom was compared with the venoms of $C$. sculpturatus from Arizona and Centruroides limpidus limpidus from Mexico using: sodium dodecyl sulfate polyacrylamide gel electrophoresis (SDS-PAGE), SDS-PAGE with hyaluronic acid (HA), turbidimetric HA, reverse-phase highpressure liquid chromatography (RPHPLC), enzyme-linked immunosorbent assay (ELISA), mouse lethal dose 50\% (LD50), and mouse effective dose 50\% (ED50).

Results: 104 specimens were collected at Caballo Lake State Park. Four were identified as $C$. sculpturatus. SDSPAGE, turbidimetric HA, and RPHPLC showed no significant difference in venom between the New Mexico and Arizona Centruroides, but did show a significant difference between these two groups and the Mexico Centruroides. SDS-PAGE/HA and ELISA assays showed no significant differences between groups. LD50 and ED50 data were similar between New Mexico and Mexico Centruroides, both being more potent and more readily reversed by antivenom than the Arizona Centruroides.

Discussion: This is the first documented envenomation by C. sculpturatus in this part of New Mexico. The abundance of specimens collected, both adult and juvenile, indicates a thriving population of C. sculpturatus east of its previously described range.

Conclusion: C. sculpturatus scorpions are located further east than previously recognized. Venom of this population is comparable in potency and antivenom binding to that of $C$. l. limpidus and more potent than venom of $C$. sculpturatus in southern Arizona.

\section{VENOM ANALYSIS OF LONG-TERM CAPTIVE PAKISTAN COBRA (NAJA NAJA) POPULATIONS}

Modahl C.

University of Arizona, Tucson, AZ, USA

Cassie.Modahl@uky.edu
Venom production facilities keep established colonies of captive snakes to obtain venom for research and antiserum purposes. Since some venomous snakes, including the black Pakistan cobra (Naja naja), have strict regulations involving importation, only a small number of initial individuals are used to construct these colonies, which are subsequently used for venom production. As a result, many are closely related to one another; most are siblings. With the use of gradient SDS-PAGE gels and reversephase liquid chromatography mass spectrometry (RPLC/ MS), venom from 15 long-term captive $N$. naja originating from two separate venom production colonies were analyzed. All the cobras in this study showed the same three-finger toxin and phospholipase A2 molecular masses, but there was a clear difference in each protein concentration. At the same elution time, the venom from $N$. naja in one colony showed a 6,756-Da protein peak compared with the cobras in the other colony that instead showed a peak of $6,783 \mathrm{Da}$. It would be interesting to examine the structure and biological properties of such closely related isoforms.

\section{METABOLOMIC PROFILE SHIFTS IN MAMMALIAN KIDNEY CELLS CAUSED BY PITVIPER VENOMS}

\author{
Morrill $\mathrm{BH}^{(1)}$, Rickords $\mathrm{LF}^{(1)}$, Mackessy $\mathrm{SP}^{(2)}$, Awada $\mathrm{M}^{(3)}$. \\ 1. Utah State University, Logan, UT, USA \\ 2. University of Northern Colorado, Greeley, CO, USA \\ 3. Thermo Fisher Scientific, Logan, UT, USA \\ dendroaspis03@gmail.com
}

Introduction: Envenomation by pitvipers frequently results in severe local edema and necrosis, with symptoms occasionally becoming systemic and life-threatening. Recent work has illuminated our understanding of the complex nature of many venoms by defining the proteome and transcriptome for several pitvipers, but effects of envenomation on tissue and cellular metabolic events remains poorly known. Because symptoms of envenomation can involve disregulation of numerous metabolic pathways simultaneously, we initiated an in vitro study of metabolomic effects of venoms.

Methods: The neutral red assay was used to calculate a median cytotoxic dose $\left(\mathrm{CT}_{50}\right)$ of $12.5 \mu \mathrm{g} / \mathrm{ml}$ for Eastern Cottonmouth (Agkistrodon piscivorus piscivorus) venom on Vero cells in culture. All samples were cultured in 5\% heavy water $\left({ }^{2} \mathrm{H}_{2} 0\right)$ media for $20 \mathrm{~h}$ prior to cell collection so that enrichment values could be calculated for all detected metabolites. Cells were cultured with $12.5 \mu \mathrm{g} / \mathrm{ml}$ of either Eastern Cottonmouth or Desert Massasauga (Sistrurus catenatus edwardsii) venoms for $4 \mathrm{~h}$ prior to cell collection; control samples (without venom) were similarly cultured. After incubation, medium samples were 
collected from all flasks, and cells were harvested. Metabolites were then extracted from the cell and media samples and prepared to be analyzed by gas chromatography-mass spectrometry. Data analysis was carried out using MassLynx 4.1.

Results: Metabolomic profiles were generated for the cell and media samples that consisted of 22 and 18 metabolites, respectively. Overall, the metabolomic profile shifts caused by the Eastern Cottonmouth and Desert Massasauga venoms were similar. In the cell samples, the metabolites that contributed most to profile differences between treated and non-treated samples were amino acids and sugars. In general, in the venom-treated samples, amino acid enrichment values were higher, while sugar enrichment values were lower.

Discussion: Increased enrichment values for amino acids in the venom-treated samples indicate that more amino acid molecules are being produced in venom-treated vs. nontreated samples. Increased production of amino acids, especially those found in the urea pathway, suggests that the cells are using more amino acids for cellular fuel when treated with venom. Conversely, the decreased enrichment values for sugars in the venom-treated samples indicate that fewer sugar molecules are being produced.

Conclusion: These findings collectively suggest that a major (in vitro) effect of Eastern Cottonmouth and Desert Massasauga venoms is to alter metabolic pathways away from carbohydrate metabolism toward using amino acids for cellular energetic needs.

\section{SCORPION ANTIVENOM ADMINISTERED VIA ALTERNATIVE INFUSIONS}

\author{
Mosier $\mathrm{JM}^{(1)}$, Hiller $\mathrm{K}^{(1)}$, Franke $\mathrm{H}^{(2)}$, Degan $\mathrm{J}^{(3)}$, Boyer \\ $\mathrm{LV}^{(2,3,4)}$ \\ 1. Departments of Emergency Medicine \\ 2. Pediatrics and 4 Pathology \\ 3. VIPER Institute, University of Arizona, Tucson, AZ, USA \\ jmosier@aemrc.arizona.edu
}

Background: In the southwest USA, the bark scorpion Centruroides sculpturatus produces venom that can lead to a potentially life-threatening reaction. Children are at risk of increased severity of effects from scorpion envenomation, including increased risk for airway compromise, systemic effects, and neurotoxicity. Children treated with antivenom both recover faster and are less likely to require hospital admission compared with supportive therapy alone. In Arizona, scorpion stings are treated under a clinical treatment protocol with Anascorp $^{\circledR}$, Centruroides (scorpion) immune $\mathrm{F}(\mathrm{ab})_{2}$ intravenous (equine), Instituto Bioclon, approved by all participating hospital's Institutional Review Board. Under this protocol, as throughout Latin America, antivenom is administered intravenously.

Case Report: A 16 month-old-female presented to the Emergency Department $2 \mathrm{~h}$ after a scorpion sting. During prehospital transportation to the ED, she developed severe neurologic symptoms, profound respiratory distress, and unstable vital signs. Prehospital and ED attempts at intravenous (IV) access failed, and an intraosseous (IO) line was placed in the proximal anterior tibia. Three vials of antivenom in $50 \mathrm{ml}$ of saline were infused through the IO over $10 \mathrm{~min}$. Within $5 \mathrm{~min}$, the patient's respiratory status improved, and intubation was averted. Vital signs stabilized immediately, and the nystagmus and writhing completely resolved. She was discharged to home from the ED after a short observation period with no treatment-related adverse events.

Discussion: In a previously reported case, multiple routes were used for antivenom administration. It is unclear how effective the intraosseous route is for aborting symptoms. This is the first known reported case with rapid IO infusion. The entire dose was given over $10 \mathrm{~min}$ with dramatic clinical impact. Alternative routes of administration are controversial in part because little is known about the bioavailability. Intraosseous access has been recommended as an appropriate alternative, after failed IV attempts in pediatric resuscitations, by the American Academy of Pediatrics and provides a method of rapid fluid and medication delivery. Future research should investigate the safety and efficacy of rapid intraosseous infusion of antivenom for pediatric resuscitations in which IV access is not possible.

Conclusions: When IV access is impossible, IO infusion may be a rapid and reasonable rescue maneuver for patients with severe scorpion envenomation.

\section{THE AMERICAN INTERNATIONAL RATTLE- SNAKE MUSEUM: A QUASI-PUBLIC VENOMOUS ANIMAL COLLECTION AND EXHIBIT}

\section{Myers B.}

The American International Rattlesnake Museum, Albuquerque, NM, USA

snakemuseum@aol.com

Background: The Rattlesnake Museum is a privately owned museum which exhibits rattlesnakes and other venomous snakes, as well as a number of other venomous and non-venomous animals. It has been in operation since 1990. It is open to the public and maintained through private funds and admission fees. There is a formal mission statement that conceptualizes it as a museum, library, and research center. The snakes are allowed to be owned and exhibited by a permit issued by New Mexico Game and Fish. 
The Collection: There are currently over 55 snakes on display, 32 of them venomous, including 28 North American rattlesnakes, three Central and South American rattlesnakes, and one non-Americas venomous snake (Cerastes cerastes; a viper of North African origin) on display. In addition, the museum holds 53 venomous snakes not on display, including various species, being held for Game and Fish following confiscation, provided by Universities or other researchers, or donated to the museum by private collectors. These currently include 46 snakes native to the USA and seven non-native species.

Other functions: The museum serves as the meeting place of the New Mexico Herpetological Society. The museum is involved in breeding, conservation, rescue, and relocation activities. In addition, the museum participates in both public and professional education efforts regarding snakes and other reptiles, speaking at libraries, to school classes, seniors, Boy Scouts, and other groups.

Managing Risk: The potential for envenomations is minimized by the following policies and procedures: (1) Using locking cages with $1 / 4^{\prime \prime}$ or $1 / 2 "$ glass; limitation in working with venomous snakes to two experienced individuals; only working in pairs; always handling venomous snakes with tools; removal of venomous snakes from cages for cleaning and maintenance; and working with venomous snakes only when the museum is closed. In the event of an envenomation, pre-existing local hospital supplies of CroFab would be sufficient for management of a bite by the North American rattlesnakes and possibly by Central American species whose range extends into Mexico. Bites by South American rattlesnakes and by other non-native venomous snakes would require antivenom to be obtained through the Antivenom Index. Optimization of the response to a possible non-native envenomation has been through coordination with the regional poison center and with an experienced clinician. To date, there have been no envenomations in the museum's 19-year history. Efforts to make potentially necessary antivenoms readily available are in progress.

Conclusion: Operation of a private museum exhibiting non-native species is feasible as a governmentallysanctioned entity, providing a public service in terms of public education, snake conservation, and safe housing of confiscated or otherwise unwanted venomous snakes.

\section{CONSERVATION OF THE ARUBA ISLAND RATTLESNAKE (CROTALUS UNICOLOR): SAVING A DANGEROUS AND LESS-THAN-POPULAR SPECIES}

Odum RA.

Toledo Zoological Society, Toledo, OH, USA

RAOdum@ aol.com
Background: Association of Zoo and Aquarium's (AZA) Species Survival Plan (SSP) for the Aruba Island rattlesnake (Crotalus durissus unicolor) has been stewarded by the Toledo Zoo for 20 years. A holistic approach has been used to develop $C$. durissus unicolor conservation efforts that have included organization partnerships within Aruba and internationally, field research projects, education programs, public relations, and conservation planning workshops. Although this species is generally docile and inoffensive, it carries very toxic venom and is capable of inflicting a fatal envenomation on an adult human. This factor was addressed through a medical workshop and the development of protocols for dealing with nuisance snakes found near human activity areas. Facilitated workshops of local stakeholders and international biologists were also conducted to identify issues that could affect $C$. durissus unicolor and then develop tactics to address areas of concern. Continuing public relations campaigns to develop an appreciation for the uniqueness of Aruba's wildlife have proven beneficial for the conservation of C. durissus unicolor on the island.

Discussion: Conservation efforts for the $C$. durissus unicolor on Aruba have been ongoing since the late 1980s. A broad approach to this work has provided a degree of success, and the outlook for the snake on Aruba is optimistic. Major parts of these efforts have included two IUCN Conservation Breeding Specialist Group (CBSG)facilitated workshops. The first in 1992 was a Population and Habitat Viability Workshop (PHVA) specifically focused on $C$. durissus unicolor, which was the basis for the designation of protected areas for the snake, legal protection, and several ecological studies. The second workshop in 2008 was a general conservation workshop (The First National Congress for the Preservation of Aruban Wildlife-WildAruba.org) to develop a Conservation Action Plan for the entire island. Parts of this plan have already been implemented. Field studies concerning the ecology of the rattlesnakes and the impact of its translocation have been performed. These studies have been used as the basis for management of the wild snake population. The translocation study dealt specifically with the issue of how to deal with nuisance snakes found around human dwellings. Studies have been undertaken and are ongoing to investigate methods of controlling the recently introduced boa constrictor to the island and to determine its impact on native species. The conservation program has had a significant education component. Teacher's workshops about Aruba's wildlife and ecology have been conducted since the early 1990s. These workshops have focused on conservation education teaching methods developed in American zoos and schools. This train-the-trainer approach implemented to maximize efficiency of education efforts. One of the most important components of these efforts has 
been a public relations program for the rattlesnake. Numerous television and radio interviews, as well as many newspaper articles, have generated a greater appreciation for the rattlesnake and Aruba's wildlife in general.

Conclusions: The successes of the conservation efforts for the Aruba Island rattlesnake are based on addressing the numerous issues that could affect the future stability of the population of snakes on the island. Considerations must be given to unique attributes for the species, such as its toxic venom and danger to people. Addressing the human aspect issues have been a significant component of these efforts. It is suggested here that the holistic approach taken in this program could be applied to efforts for many different species in other regions.

\section{VARIATION OF VENOM COMPOSITION IN WILD CAUGHT, CAPTIVE ADULT AND NEONATAL CROTALUS ATROX}

Pozarowski $\mathrm{KM}^{(1)}$, Rascòn Jr. AA ${ }^{(1)}$, Poulin $\mathrm{S}^{(2)}$, Ivanyi $\mathrm{C}^{(2)}$, Osterhout $\mathrm{JJ}^{(1,3)}$.

1. Biochemistry and Molecular Biophysics, University of Arizona, Tucson, AZ, 85721 USA

2. Arizona-Sonora Desert Museum, 2021 N. Kinney Rd. Tucson, AZ 85743, USA

3. Department of Chemistry and Biochemistry, Angelo State University, San Angelo, TX 76909, USA

john.osterhout@ angelo.edu

Background: The individual variation in Crotalus atrox venom components was analyzed in three classes: wild caught adult, captive adult, and wild caught neonatal.

Methods: Venom from individual snakes was analyzed by reversed-phase high-performance liquid chromatography (RPHPLC). RP-HPLC allows the separation and visualization of the protein components of the venoms of individual snakes.

Results: The volume of venom collected from neonatal snakes ranged from 11-30 $\mu \mathrm{l}$ while the volume collected from adults ranged from 5-245 $\mu$ l suggesting that adult snakes have the capability of delivering significantly more venom than neonatal snakes. RP-HPLC analysis indicated that there was significant individual variation within the classes and that the protein composition of neonatal snakes as a class varied significantly from that of the adults. Not surprisingly, commercial C. atrox venom more closely resembled the adult classes.

Discussion: The RP-HPLC results indicate significant differences between the neonatal snakes and the adults. Variation in response to envenomation can arise from at least three sources: variation in the amount of venom delivered, variation in the toxicity of the venom, and variation in the ability of the antivenom to respond to neutralize the individual venom components. In this study, the amount of venom delivered spanned a $49 \times$ range. Literature reports suggest that venom from neonatal snakes of various species might be slightly more toxic in animal testing than adults. The present study indicates that the protein components in neonatal snake venom might be sufficiently different from those of adult snakes that incomplete neutralization may be a significant source of response variability to envenomation.

Conclusion: Significant individual variation in the protein components of $C$. atrox venoms from wild caught adult, captive adult, and neonatal snakes was observed. As a class, the neonatal venoms were noticeably different from the two classes of adult venoms. The next logical step is to determine the specific venom components bound by antivenom.

\section{IMPACT OF DELAYED PRESENTATION, TRANSPORT METHOD, AND FIRST AID USE ON ANTIVENOM DOSAGE AT BHARATPUR HOSPITAL, CHITWAN, LOWLAND NEPAL}

Pandey $\mathrm{DP}^{(1)}$, Shrestha $\mathrm{BR}^{(2)}$, Pradhan $\mathrm{SK}^{(3)}$.

1. M.Sc. Zoology, Lecturer, Dpt. of Zoology, Birendra Multiple Campus, Tribhuvan University, Bharatpur-10, Chitwan, Nepal; Institutional Member, Parasitological Research and Socio-Environmental Development, Nepal; President, Association for Nature Conservation and Social Upliftment, Nepal

2. M.B.B.S., Consultant Medical Generalist, Head of Emergency Dpt., Bharatpur Hospital, Bharatpur-10, Chitwan, Nepal

3. M.B.B.S., General Physician, Emergency Dpt., Bharatpur Hospital, Bharatpur-10, Chitwan, Nepal

debpandey@gmail.com

Introduction: Snake envenomation is a potentially lifethreatening medical condition. This study sought to assess factors associated with the extent of consumption of anti-snake venom serum (ASVS) vials.

Objective: To chart the association of ASVS vials administered with time since bite, means of transport, and adoption of first-aid.

Methods: Admitted envenomated victims of snakebite at Bharatpur Hospital were studied consecutively by the use of pre-tested data sheets from April to September 2007. When the patient was unable to provide historical data, family members or visitors were queried. Data analysis was done based on percentage, simple arithmetic mean and Kendall's tau b's coefficient of correlation $(r)$ by the application of SPSS-16 version program. Level of significance considered $(p)$ was $5 \%$ (two-tailed).

Results: Of the total number of snakebite victims $(n=39)$, $92 \%$ exhibited neurotoxicity and $8 \%$ hemotoxicity. The case fatality rate was $22 \%(n=8)$. The range of antivenom administered to survived victims was four to 94 vials 
(average $=40.6$ vials). No ASVS was administered to viper bite victims because they got envenomed by pitvipers that inflicted them mildly. The correlation between time since bite and antivenom dosage $(r=0.269 ; p=.048)$ was found significant. Means of transportation associated with increased patient's body shaking resulted worse outcomes. The correlation between walking and antivenom dosage was found to be significant $(r=0.277) ; p=0.051)$. No victims had administration of a clinically significant first aid measure.

Conclusion: Administrations of unexpectedly large number of antivenom were evident in response to severity of envenoming and delay walking. That no victims employed effective methods of first-aid may contribute to the use of increased numbers of ASVS vials and poorer outcomes in the region. Also, early arrival to a healthcare facility improved outcomes and late arrival resulted poorer outcomes. To minimize severity of neurotoxicity, mortality, and antivenom dosage, the invaluable pressure immobilization (for elapid bites) and local compression immobilization (for viperid bites) technique of first aid awareness campaign should be immediately commenced in snakebite prone areas by concerned authorities though the dependency on traditional healing decreased slightly. Further intensive research in collaboration with adequate samples adopting predefined data collection methods should be carried out to clarify the variability of antivenom administration and affirm whether the antivenom dose will be significantly correlated with appropriate first aid methods (i.e., PI or LCI with optimal bandage sizes, stretch, and pressure for different-sized limbs), means of transport, geographical variation of snakes involved in envenomation and antivenom production, amount of venom injected or circulated in blood, appropriate antivenom type (mono- or poly-, alien or Nepalese antivenom), dosing interval (for victims with or without identification of snakes involved in envenomation), and dosage (low or high) group with effectiveness. Amount of venom injected and circulated in blood should be measured or predicted prior to estimate amount of antivenom required to cure each envenomed victims.

\section{SNAKES IN VICINITY OF CHITWAN NATIONAL PARK-THE WORLD HERITAGE SITE, LOWLAND, NEPAL}

Pandey DP ${ }^{(1)}$, Coombe $\mathrm{G}^{(2)}$.

1. M. Sc. Zoology, Lecturer, Dept. of Zoology, Birendra M. Campus, Tribhuvan University, Bharatpur-10, Chitwan, Nepal; Association for Nature Conservation and Social Upliftment (ANCSU), Nepal; Parasitological Research and Socio-Environmental Development (PARASED), Nepal

2. Living with Wildlife, Australia

debpandey@gmail.com
Introduction: In Nepal, a total of 89 species of snakes have been reported, 21 of them venomous. Because of a lack of studies, the geographic ranges of various species are unknown. Species identification is important because of the use of monospecific antivenom $\mathrm{s}$, but also because snakes contribute to the agricultural ecosystem, with potential impacts on agricultural production. Thus, it is also necessary to assess the impact of human activities on the health of snake populations.

Objective: To survey the current snakes found in Chitwan and Nawalparasi districts in vicinity of Chitwan National Park (CNP).

Methodology: A checklist regarding snake type, including local common snake names, as well as types of humansnake interactions, was used in interviews in these regions. Reports were taken for the 6-year period in 2002 to 2008 . In addition, dead specimens were also collected and studied.

Results: A total of 28 species (13 venomous) were recorded from the study area. Of the 13 venomous species, nine were considered highly venomous. Bungarus caeruleus and Naja naja were the most frequently encountered venomous snakes. There was homogenous species distribution in both districts. In addition, locals indicated that they used snake fat to heal wounds, snake skin for garments, small bags, and other uses, but that snakes were not generally a food source.

Conclusion: This study of predominantly agricultural regions, demonstrated a large number of venomous snakes. Additional studies should be conducted to determine species diversity and ongoing impact on snake populations. A public awareness campaign should be conducted at a national level to decrease intentional snake killings that may result in injury to snake populations, imbalance agro-ecosystems, and possibly diminish the agricultural productivity.

EASTERN CORAL SNAKE (MICRURUS FULVIUS FULVIUS) ENVENOMATIONS: THE TAMPA POISON INFORMATION CENTER ACTION PLAN

\section{Pittman HJ}

Florida Poison Information Center-Tampa, Tampa General Hospital, Tampa, FL, USA

traumajunkiejoe@Juno.com

Background: In 2006, Wyeth Pharmaceuticals discontinued production of North American Coral Snake Antivenin, antivenin (Micrurus fulvius; equine origin). This announcement raised concerns fueled by local media reports in 2008 regarding the management of coral snake envenomations. With all existing stocks of antivenin expiring in October 
2008, the Florida Poison Information Center-Tampa began developing an action plan to address this issue in June 2008. Discussion: Between 1998 and 2008, the Florida Poison Information Network received 470 reported cases of Eastern Coral Snake (M. fulvius fulvius) envenomation averaging $\quad 40-50$ cases annually. Approximately 26 cases annually were treated with Wyeth Antivenin (M. fulvius; equine origin), North American Coral Snake Antivenin after recommendation from the Poison Information Network equaling approximately 78 total vials administered annually (based on three-vial dose). In October 2008, all available stocks of the North American Coral Snake Antivenin would expire, and all production of the antivenin by Wyeth had already ceased. In June 2008, a phone survey of hospital pharmacies in the Tampa Poison Information Center coverage area was completed, and 142 available vials of antivenin were inventoried in the region. In addition, information regarding Bioclon, Coralmyn ${ }^{\circledR}$ AntiCoral Serum was obtained and the Medical Director was appraised of the findings. In October 2008, representatives of the Tampa General Hospital Pharmacy, Office of Clinical Research, and the Florida Poison Information CenterTampa met and developed a three-part plan to address the management of Eastern Coral Snake envenomations with the dwindling antivenin stocks and impending expiration of the current FDA-approved antivenin. The plan involved obtaining, preserving, and administering expired antivenin to patients at Tampa General Hospital; developing protocols and preparing for the emergency use of Coralmyn ${ }^{\circledR}$ anticoral serum at Tampa General Hospital as recommended by the Florida Poison Information Center-Tampa; and the planning and execution of a research study of the Coralmyn ${ }^{\circledR}$ anti-coral serum. On October 22, 2008, Wyeth Pharmaceuticals released a statement that the US Food and Drug Administration (FDA) had authorized the extension of the expiration date on a single lot of Antivenin ( $M$. fulvius; equine origin) North American Coral Snake Antivenin to October 2009. On October 24, 2008, a second phone survey was conducted of hospital pharmacies identifying only 61 available vials of the extended expiration lot number antivenin.

Conclusion: Although patients may be intubated, ventilated, and supported through an envenomation, they are also placed at risk for developing ventilator-acquired pneomonitis, adult respiratory distress syndrome (ARDS), and possible death. Antivenin remains the mainstay of envenomation management providing the best treatment option. The extended expiration of a single lot of antivenin provides only a temporary solution to a developing crisis. The Florida Poison Information-Center plan ensures appropriate treatment to envenomation victims, provides for the use of an alternative non-FDA-approved antivenin, and offers research into its use.

\section{A NEW PLACE IN THE SUN: POTENTIAL SHIFTS OF RATTLESNAKE RANGES UNDER CONDITIONS OF CLIMATE CHANGE}

\author{
Quijada-Mascareñas $\mathrm{A}^{(1,3)}$, Hearn $\mathrm{D}^{(2)}$, Boyer $\mathrm{LV}^{(3)}$, \\ Mackessy $\mathrm{SP}^{(4)}$. \\ 1. School of Natural Resources and the Environment, \\ University of Arizona, AZ, USA \\ 2. Ecology \& Evolutionary Biology, University of Arizona, \\ AZ, USA \\ 3. VIPER Institute, University of Arizona, AZ, USA \\ 4. School of Biological Sciences, University of Northern \\ Colorado, CO, USA
}

Background: Climate change will likely alter the distribution of many organisms, including venomous snakes. Of particular interest will be changes in distribution of species adapted to arid environments in the warm deserts of southwestern USA and northern Mexico. Several of the larger species found in this area, such as Western Diamondback Rattlesnakes (Crotalus atrox) and Mohave Rattlesnakes (Crotalus scutulatus), represent a significant health risk, and increased incidence of envenomations is of considerable clinical concern. Here, we present projections of the potential distribution of eight rattlesnake species of medical significance under climate change scenarios.

Methods: Our analysis is based on presence-locality databases from museum and published records. To obtain present and future rattlesnake distributions, we used the algorithm MAXENT that follows the principle of maximum entropy for modeling climatic variables to produce potential distributions. For future projections we used the climate change projections generated by the NCAR Community Climate System Model (CCSM) of the Intergovernmental Panel on Climate Change (http://www.ccsm.ucar.edu) and the WorldClim database (http://www.worldclim.org).

Results: The projections generated indicate a mixture of trends, where some species appear to expand their ranges and/or shift to different latitude, while others maintain stable or even reduced distribution in accordance with predicted climate change.

Discussion: Based on these projections, we discuss the significance of the effects of climate change in the context of the biology of rattlesnakes and, in the case of species of medical concern, the predicted epidemiological implications if the present trend continues and leads to range expansions. We couple these predicted range expanses to the potential for expanded/altered prey base utilization, which in turn could select for local adaptation in venom composition. Conclusion: If ranges expand and extend into new areas, as our projections suggest, there is considerable potential for increased conflict with human residents in the 
densely populated southwest. We recommend a program for monitoring the dispersal of rattlesnakes that predicates range expansion (i.e., monitor the expanding edge of distribution) as climate is continually modified by anthropogenic activities.

\section{HEMATOLOGIC RECURRENCE AFTER POLY- VALENT IMMUNE FAB ANTIVENOM TREATMENT FOR NORTH AMERICAN RATTLESNAKE BITE}

\author{
Ruha AM, Curry SC, Albrecht C, Smith JC. \\ Dept. of Medical Toxicology and Banner Good Samaritan \\ Poison Center, Banner Good Samaritan Medical Center, \\ Phoenix, AZ, USA \\ michelle.ruha@bannerhealth.com
}

Background: Since the introduction of polyvalent immune Fab (CroFab) for treatment of North American rattlesnake bite (RSB), "recurrence" has presented new dilemmas for practitioners. Hematologic recurrence occurs at least $24 \mathrm{~h}$ after completion of maintenance dosing, and it is unknown how late recurrence may first occur and how long patients should be followed after CroFab treatment. We previously observed that normal platelet counts and fibrinogen levels 1-2 days after CroFab did not exclude delayed hematologic abnormalities beginning on day 3 or 4 . In addition, late development of thrombocytopenia and defibrination may occur despite normal platelet and coagulation studies throughout the initial hospitalization. Few reports in the literature address hematologic recurrence, and these are limited by failure to achieve initial control, inconsistent use of maintenance dosing, and limited and often incomplete, short-term patient follow-up. Reported rates of recurrence are as low as $8.5 \%$.

Methods: We sought to determine incidence of recurrent or new coagulopathy (PT>14 s), hypofibrinogenemia $(\mathrm{Fib}<170 \mathrm{mg} / \mathrm{dL})$, and thrombocytopenia $(\mathrm{Plt}<120 \mathrm{~K} /$ $\mathrm{mm}^{3}$ ) in RSB patients treated with CroFab between 1 Jan 2005 and 31 Dec 2006. Study was approved by our IRB, and charts were identified through search of department database and hospital ICD codes. Data collected included demographics, snakebite information, laboratory studies, antivenom doses, and adverse events.

Results: Eighty patients met inclusion criteria, with hypofibrinogenemia present in $28 \%$, coagulopathy in $50 \%$, and thrombocytopenia in 34\% during initial hospitalization. Mean CroFab dose for initial control was 8.8 vials. At least six vial maintenance CroFab was given to $98 \%$ of patients. Some $84 \%$ of patients received follow-up, with the first visit a mean of 4.2 days from last CroFab dose (median, 3 days). Some $31 \%$ of patients had new or recurrent hematologic abnormalities. Some $44 \%$ of patients with initial heme-abnormalities had recurrence. Some $12.5 \%$ of patients with normal initial labs had new, lateonset hematologic abnormality during follow-up. Some $15 \%$ of recurrent or new heme-abnormalities were severe $(\mathrm{Fib}<35$ or $\mathrm{Plt}<50)$. Only one patient was retreated with CroFab. Some $90 \%$ of patients with severe recurrent or late coagulopathy or thrombocytopenia were observed as outpatients until spontaneous resolution. No adverse bleeding events occurred.

Conclusion: Recurrent or delayed-onset hematologic recurrence following CroFab treatment for RSB is very common. All patients, regardless of laboratory findings during initial treatment, require diligent follow-up until coagulation parameters and platelet counts are improving or stable. Close outpatient observation of select cases of hematologic recurrence appears to be a safe management option.

RECURRENT COAGULOPATHY AFTER CROTALUS CERBERUS ENVENOMATION TREATED WITH CROTALIDAE POLYVALENT IMMUNE FAB (OVINE) ANTIVENOM [FABAV]

\author{
Shirazi $\mathrm{FM}^{(1)}$, Racy $\mathrm{J}^{(2)}$. \\ 1. Arizona Poison and Drug Information Center, Tucson, \\ AZ, USA \\ 2. Department of Emergency Medicine, University of Arizona, \\ Tucson, AZ, USA \\ mshirazi@aemrc.arizona.edu
}

Background: Annually, there are approximately 8,000 snakebites reported to the American Association of Poison Control Centers. The Arizona Black Rattlesnake (Crotalus cerberus) accounts for an undetermined number of rattlesnake envenomations. A case report of Arizona Black Rattle snake envenomation successfully treated with Crotalidae Polyvalent Immune Fab (ovine) antivenom has been described in the literature. Multiple case reports of recurrent coagulopathy with western diamond back (Crotalus atrox) envenomation has been described in the literature. This is the first case of severe and recurrent coagulopathy attributed to The Arizona Black Rattlesnake (C. cerberus) envenomation. Case Report: A 23-year-old male presented to our emergency department within $30 \mathrm{~min}$ after Arizona Black Rattlesnake (C. cerberus) envenomation. He sustained a bite on the dorsum of his right hand by putting his hand in a pet snake's enclosure. Upon presentation, the patient was tachycardic, normotensive, and thrombocytopenic with a platelet count of 44,000/ul. Fibrinogen was $242 \mathrm{mg} / \mathrm{dl}$, and the INR was1.4. Hemoglobin and hematocrit $(\mathrm{H} \& \mathrm{H})$ were $11.7 \mathrm{~g} / \mathrm{dl}$ and $37 \%$, respectively. Antivenom therapy was initiated with ten vials of FabAV followed by two vials 
every $6 \mathrm{~h}$. The patient's fibrinogen and platelet normalized after the initial FabAV therapy with the bolus and maintenance. The INR peaked at 2.0 within the first $10 \mathrm{~h}$ and then started to trend downward to 1.0. On day 3 of hospitalization, $60 \mathrm{~h}$ after presentation, patient's platelet count dropped to 8,000/ul and the H\&H dropped to $7.1 \mathrm{~g} / \mathrm{dl}$ and $24 \%$. Although the $\mathrm{H} \& \mathrm{H}$ dropped, the patient's fibrinogen remained normal at $340 \mathrm{mg} / \mathrm{dl}$, and INR was 1.1. This was accompanied by expansion of ecchymosis from right hand and arm into the thorax and epistaxsis. Patient's thrombocytopenia was refractory to two vials of FabAV and required four to eight vials to treat the acute episode. Our patient required a total of 60 vials of antivenom and 10 days of hospitalization prior to resolution of thrombocytopenia.

Conclusion: Coagulopathy can result from C. cerberus envenomation. Recurrent coagulopathy as result of treatment with Crotalidae Polyvalent Immune Fab (ovine) Antivenom can result in significant hemorrhage and complication of clinical course requiring prolong monitor and repeated dosing with FabAV.

\section{THE RECOMBINANT DISINTEGRIN OF THE MOHAVE RATTLESNAKE}

Sánchez $\mathrm{EE}^{(1)}$, Lucena $\mathrm{SE}^{(1)}$, Cantu $\mathrm{E}^{(1)}$, Soto $\mathrm{JG}^{(2)}$, Reyes $\mathrm{S}^{(1)}$, Rodriguez-Acosta $\mathrm{A}^{(3)}$, Lopez-Johnston $\mathrm{JC}^{(1)}$, Guerrero $\mathrm{B}^{(4)}$, Perez $\mathrm{JC}^{(1)}$.

1. Natural Toxins Research Center, College of Arts and Sciences, 975 W. Avenue B. MSC 158, Texas A\&M University-Kingsville, Kingsville, TX 78363, USA

2. Biological Sciences Department, San Jose State University, One Washington Square, San Jose, CA, USA

3. Instituto de Medicina Tropical, Universidad Central de Venezuela, Caracas, Venezuela

4. Instituto Venezolano de Investigaciones Cientificas (IVIC), San Antonio, Venezuela

elda.sanchez@tamuk.edu

Many molecules found in snake venom can induce pathophysiological changes to humans and animals, causing edema, hemorrhage, and necrosis. Disintegrins are lowmolecular-weight, non-enzymatic proteins found in snake venom that mediate pathophysiological changes by binding to integrins of platelets as well as other cells with greater affinity than natural ligands such as fibrinogen, fibronectin, or vitronectin. Disintegrins are of great biomedical importance due to their binding affinities resulting in the inhibition of platelet aggregation. Moreover, disintegrins have been demonstrated to inhibit or reduce angiogenesis in tumor development and inhibit metastasis. From previous studies, the disintegrin mojastin isolated from the venom of Crotalus scutulatus scutulatus (Mohave rattlesnake) was demonstrated to inhibit ADP-induced platelet aggregation with an $\mathrm{IC}_{50}$ of $13.8 \mathrm{nM}$. Disintegrins are found in low abundance in snake venom and requires a laborious effort in the isolation process; therefore, cloning these important biomedical molecules are of great interest. By isolating a snake venom gland from $C$. scutulatus scutulatus, an expressed cDNA disintegrin gene was obtained via RTPCR. Sequencing revealed rMojastin cDNA fragment of $216 \mathrm{bp}$, and the deduced amino acid sequence of 71 amino acids are identical to native mojastin (containing an RGD binding motif). rMojastin was sub-cloned and expressed in E. coli, and the recombinant rMojastin demonstrated properties of inhibiting platelet aggregation in whole blood and platelet-rich plasma with $\mathrm{IC}_{50}$ values of 46 and $119.7 \mathrm{nM}$, respectively. rMojastin was able to inhibit the adhesion of skin melanoma cells (SK-Mel-28) to fibronectin with an $\mathrm{IC}_{50}$ of $94.6 \mathrm{nM}$ but had no effect on human urinary bladder carcinoma cells (T24). MALDI-TOF-TOF mass spectrum identified rMojastin as $7.9509 \mathrm{kDa}$ in addition to the five amino acids G-S-P-E-F at the N terminus from glutathione $S$-transferase of pGEX-4 T-1rMojastin expression vector.

\section{METHODS FOR IN VITRO EVALUATION OF VENOM-ANTIVENIN INTERACTIONS USING SIZE-EXCLUSION HIGH-PERFORMANCE LIQUID CHROMATOGRAPHY}

\author{
Sanny CG. \\ Oklahoma State University Center for Health Sciences \\ (OSU-CHS), Tulsa, OK, USA \\ charles.sanny@okstate.edu
}

Introduction: Size-exclusion high-performance liquid chromatography (SE-HPLC) separates molecules based on molecular mass and hydrated volume. SE-HPLC has been used to evaluate snake venom-antivenin interactions. Formation of venom-antivenin complexes can be detected in elution profiles. SE-HPLC of venom, antivenin, and venom-antivenin reaction mixtures can provide valuable information regarding venom-antivenin complex formation as illustrated using Crotalus atrox (western diamondback rattlesnake) venom and Crotalidae Polyvalent Immune Fab (ovine) antivenin (FabAV).

Methods: Reaction mixtures and controls. Solutions of venom, antivenin, and mixtures of venom and antivenin $(0-1.0 \mathrm{mg} / \mathrm{ml}$ of venom and/or antivenin) are incubated for at least $30 \mathrm{~min}$ at $4^{\circ} \mathrm{C}\left(1 \mathrm{~h}\right.$ at $37^{\circ} \mathrm{C}$ does not change the results). HPLC system. Minimum requirements: Elution buffer (e.g., $50 \mathrm{mM}$ sodium phosphate, $\mathrm{pH} 7.4 ; 0.15 \mathrm{M} \mathrm{NaCl}$ ); HPLC pump (flow rate, $1 \mathrm{ml} / \mathrm{min}$ ); injector $(20,25$, or $50 \mu \mathrm{L} /$ injection); SE-HPLC column (e.g., Bio-Sil SEC 250-5, Bio- 
Rad Laboratories); UV detector; data acquisition hardware and software (e.g., Waters busLAC/E interface card; EMPOWER 2 software). Data analysis. Methods of varying complexity have been used to quantitate changes in venomantivenin reaction mixture profiles compared with venom and antivenin controls. Changes in profile areas can be fit to dose-response functions thus providing estimates of maximum binding as well as concentrations of venom and antivenin at half-maximum binding.

Representative results ( $C$. atrox venom; FabAV): Complex formation was detected in all venom-antivenin mixtures. The relative molecular mass of the complexes depended on the concentrations of venom and antivenin which is consistent with molecules of FabAV having single binding sites and $C$. atrox venom components having one or more binding sites. Complex formation was essentially hyperbolic with respect to antivenin/venom or venom/antivenin concentration (mass) ratios. Binding of $C$. atrox venom to FabAV at halfmaximum (i.e., approximately half of FabAV binding sites are bound by venom) occurred at $0.07-0.09 \mathrm{mg}$ of venom/ $\mathrm{mg}$ of FabAV. Half-maximum binding of FabAV to C. atrox venom was at $8-15 \mathrm{mg}$ of $\mathrm{FabAV} / \mathrm{mg}$ venom. These binding parameters appear to correlate with antivenin protection against venom lethality as reported in the literature.

Summary: SE-HPLC is a method for evaluating venomantivenin interactions in vitro including venom and antivenin reactivity and stoichiometry of binding. SE-HPLC may be useful for comparing interactions between various venoms and antivenins including antivenin protection against venom lethality.

\section{RATTLESNAKE PREFERENCE FOR ENVENOMATED OVER NON-ENVENOMATED MICE}

\author{
Saviola $\mathrm{A}^{(1)}$, Chiszar $\mathrm{D}^{(2)}$, Mackessy $\mathrm{S}^{(3)}$. \\ 1. Department of EE Biology, University of Colorado, \\ Boulder, CO, USA \\ 2. Department of Psychology, University of Colorado, \\ Boulder, CO, USA \\ 3. School of Biological Sciences, University of Northern \\ Colorado, Greeley, CO, USA \\ Anthony.Saviola@Colorado.edu
}

Background: It has long been known that rattlesnakes of several species prefer envenomated (E) over non-envenomated (NE) mice when given a choice between two such carcasses presented side by side.

Methods: Using varying doses of lyophilized venom in deionized and distilled water, we determined the minimum amount of venom needed for Western Diamondback Rattlesnakes (Crotalus atrox) to distinguish between $\mathrm{E}$ and $\mathrm{NE}$ mice. In separate experiments, we assessed the ability of other species of pit vipers to discriminate between $\mathrm{E}$ and NE mice.
Finally, we have begun the process of fractionating whole venom from $C$. atrox in an attempt to identify the component (s) of venom responsible for this discrimination effect.

Results: The amount of venom needed for C. atrox to discriminate between $\mathrm{E}$ and $\mathrm{NE}$ mice was $7.1 \mathrm{mg}$, and this was termed the minimum perceptible dose (MPD). All species of pit vipers so far tested prefer E over NE mice, including Cottonmouths (Agkistrodon piscivorus) and Mamushi (Agkistrodon blomhoffi).

Discussion: Rattlesnake and other pit vipers' preference for E mice is undoubtedly associated with the fact that most of these snakes typically strike and release adult rodents and then need to discriminate the $\mathrm{E}$ and NE trail segments when locating the path taken by the prey as it departed from the site of attack. Rodents can travel several meters following envemonation, so that the task of locating and following this post-envenomation trail segment is non-trivial. In other words, a perceptual effect of venom that increases the salience of the $\mathrm{E}$ mouse and its trial is yet another adaptive consequence of venom for the organism producing it. Rodents envenomated by distantly related species of pit vipers are not interchangeable. That is, a mouse envenomated by $C$. atrox was not preferred over an NE mouse by Crotalus viridis and vice versa. Implications of this species specificity will be discussed along with broader implications of the general finding of preference for $\mathrm{E}$ over NE mice.

\section{POTENTIAL REGULATORY PATHWAYS FOR CORAL SNAKE ANTIVENOM LICENSURE}

Scott D.

CBER/FDA, Washington, DC. USA

Licensed Coral Snake Antivenom (CSAV) manufacture has ceased, although product is still available from Wyeth. FDA has extended the expiration date of CSAV based on testing that demonstrates continued potency of the available CSAV. Licensure of a new product would ensure availability for the treatment of envenomated patients. FDA regulations define licensure pathways for products, and all licensures require a demonstration of clinical efficacy and safety. Orphan products have been licensed under these requirements, but it is challenging to identify a specific strategy that is feasible and optimizes the time to licensure. The four frameworks under which products can be licensed are in the Table. Challenges for CSAV clinical studies to support licensure include a very low incidence of envenomations, unpredictable location of patients, need for urgent treatment to prevent neurological progression, lack of a validated surrogate marker for efficacy, and lack of systematically acquired historical control data in treated or untreated patients. Proposed surrogate markers for efficacy have included (1) effect on venom levels in patients, as correlated with lack of 
onset/progression of neurological symptoms and (2) pharmacokinetics (PK) in humans related to PK and efficacy in animal models. FDA intends to seek advisory opinions to consider clinical trial and surrogate marker issues. To assure availability in the absence of any licensed product, use of an investigational antivenin under IND can be achieved through treatment use programs. ${ }^{1}$ Licensure may be facilitated by use of the fast-track process and priority review timelines. ${ }^{2}$

Table. Frameworks for product licensure

\begin{tabular}{|c|c|}
\hline Conventional licensure ${ }^{3}$ & $\begin{array}{l}\text { Safety and efficacy demonstrated } \\
\text { in clinical trials }\end{array}$ \\
\hline $\begin{array}{l}\text { Conventional licensure } \\
\text { with validated surrogate } \\
\text { endpoint }^{4}\end{array}$ & $\begin{array}{l}\text { Efficacy demonstrated in humans by } \\
\text { effect on an endpoint shown to be a } \\
\text { marker predictive of clinical benefit (e.g., } \\
\text { cholesterol levels as a surrogate for } \\
\text { coronary artery disease/angina/myocardial } \\
\text { infarction); safety studies inhumans }\end{array}$ \\
\hline Accelerated approval $^{5}$ & $\begin{array}{l}\text { Licensure based on an endpoint that is } \\
\text { "reasonably likely" to be a surrogate } \\
\text { marker of clinical benefit, safety studies } \\
\text { in humans. Postmarketing study required }\end{array}$ \\
\hline Animal efficacy ${ }^{6}$ & $\begin{array}{l}\text { Licensure based on efficacy in an } \\
\text { animal model and safety studies in } \\
\text { humans; only in cases where human } \\
\text { studies are "not ethical or feasible" and } \\
\text { cannot be used if any other licensure } \\
\text { mechanism could be used. } \\
\text { Postmarketing study required }\end{array}$ \\
\hline
\end{tabular}

Disclaimer: The findings and conclusions in this [article, speech, or presentation] have not been formally disseminated by the Food and Drug Administration and should not be construed to represent any Agency determination or policy.

\footnotetext{
${ }^{1}$ Code of Federal Regulations: 21 CFR Part 312, Subpart B, (21 CFR 312.34-35)

${ }^{2}$ At www.fda.gov/oashi/fast.html (accessed: February 11, 2009)

${ }^{3}$ Code of Federal Regulations: 21 CFR part 314, subpart D (21 CFR 314.126)

${ }^{4}$ Discussed in the Federal Register, volume 57, no. 239, December 11, 1992: 58942-58945

${ }^{5}$ Code of Federal Regulations: 21 CFR part 601, subpart E

${ }^{6}$ Code of Federal Regulations: 21 CFR Part 601, subpart H
}

\section{NATIVE U.S. VENOMOUS SNAKE EXPOSURES REPORTED TO THE AAPCC DATABASE, 2001-2005}

Seifert $\mathrm{SA}^{(1)}, \mathrm{MD}$, Boyer $\mathrm{LV}^{(2)}$, Rogers $\mathrm{JR}^{(1)}$, Benson $\mathrm{BE}^{(1)}$.

1. University of New Mexico Health Sciences Center and New Mexico Poison Center, Albuquerque, NM, USA

2. University of Arizona VIPER Institute and Arizona Poison and Drug Information Center, Tucson, AZ, USA sseifert@ salud.unm.edu
Background: Differences in victim demographics, clinical effects, managements, and outcomes among native viperid (rattlesnake, copperhead, and cottonmouth), and elapid (coral snake) species have not been systematically characterized.

Methods: The database of the American Association of Poison Control Centers from 2001 through 2005 was analyzed.

Results: Between 2001 and 2005, there were 23,676 human exposures (average $=4,735$ per year) to native venomous snakes in the USA reported to US poison centers in all states except Hawaii. Some $98 \%$ were to viperid snakes and $2 \%$ to elapids. Overall, $77 \%$ of victims were male, $70 \%$ were adults $>20$ years, and $12 \%$ were aged less than 10 years. Sixty-five cases involved pregnant women, with rattlesnake bites resulting in moderate or greater effects in over $70 \%$. The overall hospital admission rate was $53 \%$. Outcomes were generally more severe with rattlesnake and copperhead envenomations and in children $<6$ years of age. The fatality rate of reported cases was $0.06 \%$. Coral snakebites have a similar hospitalization rate as rattlesnake envenomations, but in the context of available antivenom, outcomes have generally been good.

Discussion and Conclusions: Native US venomous snakebite results in considerable morbidity and mortality. Rattlesnake and copperhead envenomations and those in children $<6$ years of age produce the most severe outcomes, but coral snakebites result in similar hospital admission rates. The impending loss of coral snake antivenom may result in significant changes in outcomes from these envenomations. The existing exotic antivenom system may provide one mechanism for access to foreign antivenoms with efficacy against US coral snakes, but may be neither an ideal nor a long-term solution.

\section{RAPID TRANSPORT OF VICTIMS SLASHES SNAKE BITE FATALITIES IN RURAL NEPAL}

\section{Sharma SK. \\ B P Koirala Institute of Health Sciences, Dharan, Nepal drsanjib@yahoo.com}

Background: Envenoming after elapid snake bites are a major public health problem in southern Nepal. Many patients in rural areas die because they reach health centres too late due to the lack of adequate transport means. We evaluated the impact of a community-based intervention which aimed at decreasing the delay between snake bite and antivenom treatment.

Methods: In the first trimester of 2004, health education sessions on snake bites were conducted in four target villages of south-eastern Nepal. In addition, from April to October 2004, 40 motorcycle owners volunteered to transport snake bite victims to a specialized treatment 
centre. Pre- and post-intervention surveys were conducted in the four villages to assess the incidence and mortality of snake bites and to determine health-seeking behaviours. The medical records of the treatment centre were also reviewed to establish the characteristics of snake bite cases admitted before and after the intervention.

Findings: The incidence of snake bites decreased from $503 / 100,000$ during the summer of 2003 (pre-intervention) to $315 / 100,000$ during rainy season of 2004 (post-intervention). Snake bite case fatality rate dropped sharply after the intervention (relative risk of fatal outcome, $\mathrm{RR}=0.051$, [95\% CI $0.007-0.37] ; p<0.0001)$ while it remained constant in control villages. Finally, snake bite victims consulted traditional healers less often in 2004 compared with 2003 ( $8 \%$ versus $21 \%$; $p<0.001)$.

Interpretation: Simple educational messages and promotion of immediate transport to health centre significantly decreased the number of fatalities due to snake bites in remote rural areas.

\section{A MODEL OF EMPOWERING PARAMEDICS IN THE MANAGEMENT AND RESEARCH IN SNAKEBITE IN RESOURCE POOR SETTING- 10 YEARS OUTCOME}

\author{
Sharma S K ${ }^{(1)}$, Shah $\mathrm{C}^{(2)}$. \\ 1. B P Koirala Institute of Health Sciences, Dharan, Nepal \\ 2. Snakebite Treatment Center, Red Cross Society, Damak, \\ Nepal \\ drsanjib@yahoo.com
}

Background: Snakebite is a major health problem of rural Nepal. Qualified medical doctors are non-existing in rural areas, and access to ASV is limited leading to high mortality due to snakebite envenomation. Structured training in the management of snakebite to paramedics may help reduce mortality, providing access to treatment in rural area.

Methods: A snakebite treatment center was initiative in 1998 in Red Cross Society, Damak, in eastern Nepal targeting catchment area of highly snakebite-prone regions. A structured training course was conducted for a group of paramedics (06 to start with) on the management of snakebite with emphasis on early detection of envenoming, indication of anti-snake venom serum (ASVS), adverse effects of ASVS, and referral with ambubag ventilation. This initial training was reinforced every year at the beginning of rainy season. They also had access to telephonic consultation with the expert from BP Koirala Institute of Health Sciences (BPKIHS) - the only tertiary center of the region. Since 2002, the paramedics have also received training in snakebite-related research in this region. Results: The number of victims attending the center with suspected snakebite envenomation varied from 725 in 1998 to 1,054 in 2007 . Percentage of patients with neurotoxic envenoming ranged from $6 \%$ to $10 \%$. Average antivenoms consumption in cases with neurotoxic envenomation ranging from nine vials to 15 vials was also low in this center in comparison to hospitals of Nepal. Mortality was also low from $3 \%$ to $5 \%$ as compared with higher mortality (up to $28 \%$ ) in district and zonal hospital of Nepal. Apart from management of snakebite, the center is also involved in snakebite-related research like community-based epidemiological study, motor cycle volunteer program in reduction of mortality related to snakebite, and community education in prevention and treatment of snakebite in partnership with various institutes.

Conclusions: Empowering paramedics in resource poor setting of eastern Nepal led to establishment of a snakebite management and research center with reduction of mortality related to snakebite in center and in community.

\section{SCORPIONS OF THE SOUTHWESTERN USA: BIODIVERSITY, ECOLOGY, AND NATURAL HISTORY}

Sissom WD.

West Texas A\&M University, Canyon, TX 79016, USA dsissom@wtamu.edu

The fauna of scorpions in the USA currently includes five families, 12 genera, and 88 species. Over $90 \%$ of these species occur in the four southwestern states bordering Mexico (Texas, New Mexico, Arizona, and California). The most diverse family is the Vaejovidae with seven genera and 72 species, a group restricted to the North American continent. Although scorpions are generally associated with desert habitats, many species inhabit grasslands and forested habitats. In the Southwest, scorpions can range from below sea level (Death Valley) to 9,000 ft. in elevation (mountains of Arizona and New Mexico). Centruroides sculpturatus Ewing (Buthidae), found in western New Mexico, much of Arizona, several southeastern counties of California, and in extreme southern Utah, is the only medically important species in the USA. Aspects of scorpion population and community ecology, activity patterns, and behavior bear relevance to their interactions with humans.

\section{DETECTION OF FEMTOGRAM AMOUNTS OF BROWN RECLUSE VENOM BY ELISA USING "SUPER-POLYCLONAL" ANTIBODIES}

\author{
Stoecker $\mathrm{WV}^{(1)}$, Green $\mathrm{JA}^{(2)}$, Larkin $\mathrm{KA}^{(3)}$, Gomez $\mathrm{HF}^{(4)}$, \\ McGlasson $\mathrm{D}^{(5)}$. \\ 1. SpiderTech, Rolla MO \\ 2. Agricultural Sciences, U MO Columbia, MO, Envirologix, \\ Inc., Portland, ME, Emergency Medicine, U Michigan, Ann \\ Arbor, MI, Lackland Air Force Base, TX \\ wvs@mst.edu
}


Background: Brown recluse bites are the source of considerable morbidity and occasional mortality. Misdiagnoses, including skin cancer, severe infections, and a variety of treatable illnesses are common. A non-invasive test for the presence of venom on the surface of the skin is clinically needed.

Methods: Polyclonal antibodies raised in New Zealand white rabbits by the methods of Gomez were venomaffinity purified, yielding "super-polyclonal" antibodies. Swabs and control swabs were taken from brown recluse spider bite victims and inflammatory spider bite mimics.

Results: $85 \%$ of the spider bites rated "probable" were identified by the super-polyclonal antibodies. No detectable venom quantities were seen in any of 60 in vivo control specimens. Cross-reactions from 14 other venoms were not seen in vitro. The standard curve for the super-polyclonal ELISA shows separation of femtogram amounts of venom from background. Studies in humans and rabbits show detectable venom 8-14 days post-envenomation.

Conclusions: The new ELISA shows promise for noninvasive clinical application of spider bite identification.

\section{THE SITUATION OF SNAKEBITE ENVENOMATION IN NEPAL}

Thapa $\mathrm{CL}^{(1)}$, Pandey $\mathrm{DP}^{(2)}$

1. General Physician \& Toxinologist, District Health Office, Ministry of Health and Population, Nepal Government, Nepal

2. Lecturer, Dept. of Zoology, Birendra Multiple Campus, Tribhuvan University, Institutional Member, PARASED, Nepal; President, ANCSU, Nepal

debpandey@gmail.com; paudel_dr@hotmail.com

Introduction: Over 1,000 snakebite envenomations (excluding Viperidae bites) and 200 deaths take place annually in Nepal. Lowland Nepal (100-300 m above sea level) is highly prone to krait and cobra bite envenomations; hill and mountain areas are prone to Viperidae bite envenomations.

Methods: The retrospective study of envenomed victims treated with anti-snake venom serum (ASVS) and reported to Epidemiology Disease Control Division (EDCD), Kathmandu, from health institutions throughout Nepal during 2000-2005 was carried out in January-June 2008. Pitviper bite victims were not treated with ASVS. Hence, it excluded Viperidae bites except Russell's viper bites. Medicos and paramedics followed dose of antivenom prescribed in national protocol. The information so obtained were collated, compiled, calculated, and analyzed by the application of Microsoft excel and illustrations.

Results: The mortality of snakebite envenomation was decreasing from $18.76 \%$ in the year 2000 to $13.04 \%$ in 2005. Male victims were found greater in proportion in respective years. Snakebite envenomation aged above 15 years exceeded by more than two times in comparison to victims aged below 15 years. Krait bite was the most prominent factor of envenomation. The largest number of snakebite envenomations occurred during the hours 24:00 to $06: 00$, the facts behind which were habit (nocturnal) and habitat (in and around residential area) of Krait. It was reported that more than $65 \%$ victims had extremity bites. The anti-snake venom administration rate was decreased gradually from average of 16.61-13.59 vials/ envenomed victims in 2000 to 2005 , respectively, even though antivenom administration varied greatly in different treatment centers. July and August was the most peak time of snakebite envenomation.

Conclusion: Snakebite management in Nepal is slightly improving. Snakebite management and data keeping are poor for elaborative description of snakebite epidemiology in Nepal. People should be made aware of first aid to snakebite, preventive measures to snakebite, habit and habitat of prevalent venomous snakes. Snakebite issue should be made a specific notable disease and prioritized as national public health problems.

\section{PLANTS AGAINST SNAKE ENVENOMATION}

Vejayan $\mathrm{J}^{(1)}$, Jamunaa $\mathrm{A}^{(1)}$, Iekhsan $\mathrm{O}^{(1)}$, Mohd Ilham $\mathrm{A}^{(2)}$, Ismail $\mathrm{N}^{(2)}$, Ambu $\mathrm{S}^{(3)}$, Halijah $\mathrm{I}^{(4)}$, Awang $\mathrm{K}^{(5)}$.

1. School of Medicine and Health Sciences, Monash University Sunway Campus, Jalan Lagoon Selatan, 46150 Bandar Sunway, Selangor, Malaysia

2. Pharmaceutical Branch, Biotechnology Division, Forest Research Institute Malaysia, 52109 Kepong, Selangor, Malaysia

3. International Medical University, 126, Jalan 19/155B, Bukit Jalil, 57000 Kuala Lumpur, Malaysia

4. Institute of Biological Sciences, University of Malaya, 50603 Kuala Lumpur, Malaysia

5. Chemistry Department, Faculty of Science, University of Malaya, 50603 Kuala Lumpur, Malaysia

jaya.vejayan@med.monash.edu.my

Background: Many plants have been traditionally used against snakebite, and some have been proven scientifically. In our study, we have also demonstrated convincingly the scientific evidences of the usage of one plant, Mimosa pudica (MPT) for its in vitro capabilities. However, the plant fell short just as many other plants in its in vivo application in comparison to antivenom.

Methods: (A) In vitro studies-incubation of venom and various plant extracts at $37^{\circ} \mathrm{C}$ followed by i.p. injection into mice, (2) double immunodiffusion technique, (3) Two dimensional electrophoresis (2-DE) comparison of venom and supernatant of venom-MPT, (4) Neutralization of 
venom by MPT observed using Bradford assay; (B) In vivo study-rescue experiment, $2 \mathrm{LD}_{50}$ of venom i.p. injection into mice followed by i.v. injection of MPT.

Results: (A) In vitro studies-(1) Among the 17 plants investigated against Naja kaouthia, only Mimosa pudica showed $100 \%$ survival of all mice. MPT also showed $50 \%$ or more ability in neutralizing the $2 \mathrm{LD}_{50}$ toxicity of other venoms, namely Ophiophagus hannah, Bungarus candidus, Bungarus fasciatus, and Calloselasma rhodostoma. (2) Results of the double-immunodiffusion study showed binding capabilities between MPT and venom with the formation of venom-sample interaction precipitin line, (3) 2-DE on MPTtreated venom showed missing of protein spots, among which included phospholipase $\mathrm{A}_{2}$ identified with MALDI-TOF MS, as compared with gel of venom alone, (4) The \% neutralization obtained reduced in relationship to the decrease in MPT concentration used to incubate with the venom; (B) In vivo study - all mice unable to be rescued by MPT but the group of mice attempted with antivenom showed $100 \%$ survival.

Discussion: The screening of various plant extracts though identified MPT with potential neutralization activity against snake venom the in vivo results showed otherwise. The action of MPT can be rationalized to be due to non-specific binding based on results obtained from the doubleimmunodiffusion technique, 2-DE, and by using Bradford reagent. This was further evident as it failed to neutralize the lethal venom in vivo as compared with antivenom.

Conclusion: Many plants though been traditionally recognized for snakebite and promising in their in vitro neutralization have, however, failed in their in vivo studies due to non-specific binding towards proteins.

\section{THE MYTH OF THE BROWN RECLUSE SPIDER: MYTHCONCEPTIONS, MYTHIDENTIFICATIONS, MYTHDIAGNOSES}

\author{
Vetter RS. \\ Department of Entomology, University of California, \\ Riverside, CA, USA \\ rick.vetter@ucr.edu
}

Background: For decades, medical diagnoses of loxoscelism (i.e., brown recluse spider bites) have been common throughout North America. Oftentimes, these occurred in portions of the continent where Loxosceles spiders are rare or have never been verified.

Methods: Various studies examined the following biological and medical aspects associated with recluse spider envenomations: (1) the distribution of Loxosceles spiders, (2) identification and misidentification of spiders as recluses by the medical community and the general public, (3) dermonecrotic conditions misdiagnosed as loxoscelism, and (4) the prevalence of loxoscelism diagnoses compared with Loxosceles spider distribution in a particular geographic area.

Results: Loxoscelism has been greatly overdiagnosed in North America over the last half of the twentieth century.

Discussion: These studies generated evidence-based research to support opinions that have been presented to convince the medical community to consider the spectrum of differential diagnoses for dermonecrosis when patients present with skin lesions. The medical reliance on recluse spiders as an etiology is waning as more accurate information is disseminated about the limited distribution of Loxosceles spiders in North America along with greater awareness of the myriad of conditions that manifest in dermonecrosis. However, loxoscelism misdiagnoses and spider misidentifications continue to occur.

Conclusion: Loxoscelism diagnoses are best relegated to areas of North America where recluse spiders are historically common, abundant, and verifiable. As physicians consider the many etiologies of necrotic skin lesions, health care will improve.

\section{CHALLENGING SNAKE BITE MANAGEMENT}

Warrell DA.

Nuffield Department of Clinical Medicine, University of Oxford, Oxford, UK

david.warrell@ndm.ox.ac.uk

Snake venom lethality: Snakes that possess the most lethal venoms, judged by mouse lethality and maximum yield, do not necessarily cause the greatest medical problems, as demonstrated by that reclusive inhabitant of Australia's arid interior, the much-hyped inland taipan (Oxyuranus microlepidota).

Challenging individual cases: (1) The Vikings sometimes executed their prisoners by throwing them into a pit of vipers (Vipera berus; but not a pit viper), the sole indigenous venomous snake in many north-west European countries. Do not despise it! Its venom can cause rapid cardiovascular failure. (2) Beautiful, bulky, rainforest Gaboon vipers (Bitis gabonica and Bitis rhinoceros) are rarely provoked to bite but can produce devastating local and systemic envenoming. (3) Human victims of black mamba (Dendroaspis polylepis) bite, seldom reach hospital alive. Dendrotoxins exert unusual and devastating neurotoxic effects. (4) The clinical syndrome of coral snake (Micrurus) envenoming is expanding. A case of envenoming by South American coral snake (Micrurus lemniscatus helleri) revealed unexpected venom properties.

Species responsible for greatest human morbidity and mortality: In areas where I have worked, the most important causes of snake bite mortality and morbidity are saw-scaled vipers (Echis ocellatus) in West Africa, com- 
mon lanceheads (Bothrops atrox) in the Amazon region, kraits (Bungarus), and Russell's vipers (Daboia siamensis and Daboia russelii) in South Asia and taipans (Oxyuranus scutellatus canni) in Papua.

Snake bite management: There is no room for complacency! As in other branches of clinical toxinology, twentyfirst century snake bite management suffers from a limited evidence base, uncritical attitudes to clinical observations, rigid adherence to outworn traditional concepts, a poor understanding of pathophysiological mechanisms and lack of dialog and collaboration with laboratory scientists. Antivenom is at the core of effective management but, even in the USA, the design and provision of antivenoms for the treatment of bites by indigenous and exotic species is sub-optimal. A WHO initiative, launched by publication of "Rabies and envenomings. A Neglected Public Health Issue" in 2007 and the forthcoming "WHO Guidelines for the Production, Control and Regulation of Snake Antivenom Immunoglobulins", aims to improve antivenom production quantitatively and qualitatively, with a special focus on the needs of Africa and the appropriate use of this scarce resource through training of health care personnel.

Conclusion: Clinical toxinology must seek to improve prevention, diagnosis, and treatment of envenoming through improved understanding of epidemiology and pathophysiology.

\section{MANAGING ENVENOMATIONS IN ADVERSE ENVIRONMENTS}

\author{
Warrell DA. \\ Medical Advisor to the Royal Geographical Society and \\ Earthwatch International \\ david.warrell@ndm.ox.ac.uk
}

Introduction: Some of the world's most interesting and remote lands and waters are infested with venomous snakes, fish, arthropods, cnidarians, and other dangerous animals. Indigenous communities inhabiting tropical countries are most affected, but scientific field workers, treckers, cavers, and divers may be at risk and even climbers may be exposed, during their lowland approach to the summit or at medium altitude.

Prevention and Preparation: Know the habits and habitats of the local venomous fauna, wear protective shoes and clothing, use a light at night, sleep off the ground or under a tucked-in mosquito net, train in first aid, and avoid handling or provoking dangerous animals. Depending on the location, purpose of the expedition/activity and availability of medically trained personnel, it may be prudent to carry equipment and drugs, including antivenom, to deal with venomous bites and stings. Local medical facilities should be evaluated in advance. When the disaster happens is not the time to practise protocols and procedures.
Management problems created by adverse environments: Modern satellite communication has revolutionised telemedicine, but on-the-spot assessment of the bite/sting victim in a remote location remains challenging. Species diagnosis may be impossible; team members may lack experience of clinical features of envenoming, and yet important decisions must be made rapidly: Diagnosis? First aid? Immediate evacuation? Envenoming or anaphylaxis? Control of symptoms? Give antivenom? The use of antivenom in remote locations is frought with uncertainties and risks. There may be rare occasions when it is justifiable to give antivenom by a sub-optimal route (intramuscular rather than intravenous) if available medical skills are limited. Rapid passive transport of the victim to medical care is a priority. Trust in air evacuation may be misplaced and be associated with fatal delays if terrain or weather are hostile.

Case histories: To illustrate some of these difficulties, cases of envenoming in remote parts of Surinam, Nigeria, Burma, New Guinea, Colombia, Peru, Brazil, and the USA are analysed and practical wisdom is distilled.

Reference Books: Auerbach's "Wilderness Medicine" 2007 or Warrell's "Oxford Handbook of Expedition and Wilderness Medicine" 2008.

Conclusion: Envenoming is a special risk of some remote and adverse environments. The best approach is thorough education and preparation in advance of the expedition.

\section{A CRITICAL OVERVIEW OF MEDICALLY SIGNIFICANT "COLUBRID” BITES}

Weinstein $\mathrm{S}^{(1,2)}$.

1. Department of Clinical Toxinology, Women's and Children's Hospital, 71 King William St, Adelaide, South Australia 5001

2. Department of Internal Medicine, Clinic 275, Royal Adelaide Hospital, 275 North Terrace, Adelaide, South Australia 5000

venfraction@yahoo.com

Background: The majority of extant ophidian species belong to the superfamily Caenophidia (=Colubroidea). This includes all of the snakes such as viperids, elapids, and atractaspids responsible for envenoming that produces well-recognized mortality and morbidity in humans. A large number of caenophiodian species have been traditionally grouped in an artificial family, the Colubridae, for convenience. Although the majority of this taxonomically fluid assemblage is not known to be venomous biologically or clinically, the bites of a number of species have produced effects in humans. These effects range from insignificant or mild local injuries to fatalities. An unknown number of these taxa possess a Duvernoy's gland that produces variably toxic secretions 
released under low pressure (due to a lack of muscle insertion on the gland). Some of these snakes possess enlarged maxillary teeth that may be grooved, but never canaliculate.

Methods: This presentation broadly considers representative examples of recent (emphasizing 1975-2008) case reports describing medically significant effects of bites from some of these snakes.

Results: Case reports have involved at least 55 "colubrid" genera. Published cases are often reported by non-medically qualified authors and frequently lack detail sufficient for accurate evaluation of medical risk presented by a given species. Lack of verification of the identity of culprit specimens has occasionally led to incorrect assignment of risks. Some cases propagated in the literature infer fatal consequences of bites inflicted by Tachymenis peruviana or Philodryas olfersii without providing any data supporting the implied outcome. The life-threatening risks of venomous colubrine genera such as Dispholidus (boomslang) and Thelotornis (African bird or vine snakes) and that of natricids such as Rhabdophis (keelbacks) are well-established by clear clinical evidence. Bites from these species cause consumptive coagulopathy and hemorrhagic diathesis. Other taxa such as Boiga irregularis (brown tree snake) and Philodryas ssp. (South American racers) have been involved in a relatively large number of bites, but the precise etiology of the clinical effects remains unclear. Bites from additional species such as Malpolon monspessulanus (Montpellier snake) have produced cranial nerve palsies in humans. However, the very limited number of such cases indicates a need for cautious evaluation of the risks posed by these snakes.

Conclusions: In order to determine and assess the potential medical risks presented by snakes in this assemblage, bites must be appropriately clinically evaluated and documented with careful attention to verified identification of the taxa involved. Post-synaptically active neurotoxins isolated from Duvernoy's secretions of some colubrid species (e.g., $B$. irregularis, Boiga dendrophila, Coelognathus radiata) are of uncertain clinical significance due to their likely preyspecific activities for avian and saurian species.

\section{RISKS OF ENVENOMATION TO ZOOKEEPERS}

White J.

Women's \& Children's Hospital, Adelaide, Australia julian.white@adelaide.edu.au

Background: Reptile keepers with collections of venomous snakes, as a group, have a reputation in the medical profession and perhaps the general community, as risk takers with a poor safety history, though this is clearly inappropriate for zookeepers. Certainly, some of what we know today about snakebite has been learned from managing cases of exotic and illegitimate envenoming. However, this is not an entirely negative experience because this knowledge has helped inform us and improve treatment responses, applicable to all victims of bites by any particular species or species group. Furthermore, there is evidence that, with a correct approach, keepers of venomous snakes can have a very low rate of bites and good outcomes because of prompt and appropriate responses, both first aid and hospital care.

Snakebite Risks: The risks from snakebite are many, but can be categorised either in terms of outcome or system affected. An outcome categorisation includes short-term effects (death, pain, local, and/or major organ damage, lost work time) and long-term effects (permanent disability/loss of function of limb or organ system, loss of limb/digit, inability to work with snakes, or inability to work again). A system categorisation includes local effects (swelling, necrosis, other regional damage) and systemic effects (neurotoxicity/paralysis, myolysis, coagulopathy/bleeding, renal damage/failure, shock, cardiac damage/failure, and secondary organ damage), which can then be sub-classified into short- and long-term effects.

Mechanisms of Exposure: The more common "causes" of captive snakebite accidents include handling the snakes, inattention or distraction (beware the media), inadequate training/experience, misjudging the "safe" strike distance, feeding the snake, failing to notice the position or attitude of a snake, drunkenness/drugged/unwell, or simple and foolish "bravado". Particular risk activities include cleaning out a cage, catching snakes, feeding, ministering to a sick snake, extracting venom, and assisting the media in filming/photography.

Preparation for and Response to Envenomations: The best treatment is always prevention, so identifying risks and establishing protocols to minimise risks is a major priority in the safe snakehouse. In general, there are clear differences in bites, between professional zoo keepers (snake ID accurately known, prompt effective first aid, management plan, and antivenom available, no complicating factors such as inebriation) and private snake keepers (snake ID sometimes uncertain, often ineffective and late first aid with delayed presentation to hospital, no management plan or antivenom, sometimes complicating factors such as inebriation). Have Standard Operating Procedures (SOPs) for every potentially risky activity. When a bite occurs, carefully debrief and determine if the relevant SOPs need modification. Despite the best protocols and standards, occasionally the unexpected can happen, so procedures must be in place to manage a bite. Develop printed management plans, which should include details about the snake and its clinical effects, correct first aid, appropriate antivenom and where to source it, and (if possible) a medical management protocol developed with a clinical toxinologist (not a "keen" local doctor with an "interest" in snakebite, but no clinical toxinology training). These critical data sheets, likely to be several pages long, 
should be stored on the snake cage, so that these will be instantly accessible if a bite occurs, ready to be referred to and sent with the patient to hospital. Also on the cage, or very close by, should be appropriate first aid material and a warning buzzer to alert others that an accident has occurred. The wise snake house/keeper develops and maintains a good relationship with key medical personnel in the region, likely to be involved if a bite occurs. Do not rely on setting up such a rapport only once the bite has happened. Equally, determine beforehand who you would consult, or ask to be consulted, as a clinical toxinology expert. If possible, involve that person(s) in developing your snakebite management protocol for each snake species. Lastly, enjoy keeping venomous snakes; do not just be terrified of them.

\section{ENVENOMATIONS IN REMOTE AREAS}

White J.

Women's \& Children's Hospital, Adelaide, Australia julian.white@adelaide.edu.au

Background: Envenoming in remote areas can pose special challenges to all concerned and can be associated with an increased potential for suboptimal outcomes. Scientific research in remote areas, a vital part of our understanding of our planet and the resources it offers us, is both necessary and entails a risk of envenoming. That risk is moderated by the nature of the local venomous fauna and the type of research activity undertaken. Someone collecting live specimens, including snakes, is at higher risk. Equally, there are many other users of/visitors to remote areas, such as those prospecting, working in the mineral resources sector, and tourists. Most of these people will have only limited understanding of or planning for the risk of envenoming; therefore, in most cases of bites/stings in remote areas, the quality of the initial local response will be suboptimal. This implies that from the outset, the level of care is likely to be compromised, and this will only be exacerbated by the limited local treatment resources and the large time delay likely in accessing more comprehensive care. Given that, in most cases of major envenoming, time to definitive treatment has a major impact on outcome, this can clearly present problems for remote location cases.

Management Strategies: As in most areas of medicine, there are two main management strategies: prevention and acute care. Prevention is particularly important for remote area envenoming, but matching preventative advice/training with prospective users may be problematic. A common request is to take antivenom when visiting remote areas, a request most often best denied because of the many issues surrounding appropriate and safe use and storage. Involvement in acute management may commence when the initial call for help is received, and it is important to ensure those giving advice are either expert or have ready access to resource materials required to give appropriate advice. In general, this is best achieved by having snakebite management protocols in place and regularly updated.

The Australian Model: Australia is an example of a "westernised" nation with high-level medical care, but many remote areas with significant snakebite risks. Though hardly common, every year, there are significant snakebites in remote areas. Several example cases will be discussed, involving bites by species such as inland taipans, mulga snakes and tiger snakes. The vital role of remote air ambulance services, such as the Royal Flying Doctor Service, air retrieval services and air ICU services in improving outcomes is recognised. One key clinical management issue is timing and selection of antivenom in remote area envenoming; the risk versus benefit decision about immediate versus delayed administration which must be carefully tailored to each case individually because circumstances can be so varied. Ready accessibility of antivenom is another key component, as is choice of first aid. For an envenomed patient in a remote location, the comparative risks of different first aid methods must be weighed against the risks of delayed definitive care of major envenoming. This may lead to a quite different choice, compared with standard community advice. In particular, preventing potentially lethal systemic envenoming may take precedence over concerns about long-term bitten limb viability.

\section{THE WORLD HEALTH ORGANIZATION GLOBAL ANTIVENOM INITIATIVE}

White J.

Women's \& Children's Hospital, Adelaide, Australia julian.white@adelaide.edu.au

Background: Antivenom is one of three key determinants in optimising outcomes for envenomed patients; the other two are training of health workers and provision of adequate health care resources in areas of need. Since antivenom, essentially an antidote to venom, is a pharmaceutical product, it can be subjected to control of standards to improve quality. It is therefore, potentially, the easiest of these three determinants for a global health body, such as the World Health Organization (WHO) to influence. The WHO has a history and a substantial experienced expert bureaucracy around setting standards for pharmaceuticals, including blood products.

Antivenom: Antivenom, as a refined antibody fraction, falls within the broad classification of blood products. The role of antivenom in achieving optimal outcomes for envenomed patients is sometimes controversial and often unsubstantiated by modern-style clinical trials, but the overwhelming consensus of expert medical opinion is that antivenom is a key factor in envenoming treatment.

The Need: Ensuring that appropriate antivenoms with adequate species/toxin coverage and good safety character- 
istics are available where needed and are affordable within the context of the communities concerned is an important goal for the WHO. The recent inclusion of snakebite on the WHO list of neglected tropical diseases represents both a global recognition of how important snakebite is as a health issue and a testament to the immense effort made by concerned toxinologists and others to have this ongoing human tragedy, affecting mostly the poor rural tropics, recognised and remedied. These individuals have lobbied the WHO for many years, but, in 2007, a new effort was established by WHO to examine the issue of antivenom production standards. This has culminated in production of a definitive document guiding all aspects of antivenom production, which can be used by governments to regulate production, and producers to improve production towards best practice.

The Initiatives: The thrust of the WHO work and document focuses equally on antivenom, training and health resources, in separate initiatives. The WHO antivenom guideline establishes crucial minimum standards for producing effective antivenoms and details recent cost-effective methods for production. It is clear that many antivenoms available do not meet reasonable standards, partly because of inadequate attention to key steps that are relatively amenable to economically sustainable change. The WHO document will provide governments and producers a template to drive change towards better products, possibly lowering costs over the medium to long-term. The WHO antivenom guidelines are just one element in a thrust to improve snakebite treatment. The recent "Global Issues in Clinical Toxinology Conference" in Melbourne established a proposal for a Global Snakebite Initiative. As a result, the International Society on Toxinology (IST) has formally adopted two initiatives directly focused on this area and will now act as the global expert sponsoring organisation to champion these. The initiatives are the "Global Snakebite Initiative" and the "Clinical Toxinology Training Initiative". Together, they form a framework for tackling all three key determinants in improving snakebite outcomes. To succeed, the IST will need support from all groups involved in toxinology and venomous animals.

\section{EASTERN DIAMONDBACK RATTLESNAKE ENVENOMATION OF DOGS: 31 CASES (1982-2002)}

\author{
Willey $\mathrm{JR}^{(1)}$, Schaer $\mathrm{M}^{(2)}$. \\ 1. Oviedo, Florida, USA \\ 2. University of Florida College of Veterinary Medicine, \\ Gainesville FL, USA
}

Schaer@vetmed.ufl.edu

Background: The main purpose of this study is to describe the clinical features of Eastern diamondback envenomation in the dog.

Methods: The case records of 31 dogs examined at the University of Florida College of Veterinary Medicine's
Veterinary Medical Center (UFVMC) that were treated for Eastern diamondback rattlesnake envenomation during the period 1982 through 2002 were reviewed. Criteria for inclusion were confirmed identification of the snake as an Eastern diamondback rattlesnake by the owner and compatible clinical lesions. Each dog also was from a region known to be indigenous for the Eastern diamondback rattlesnake. The data reviewed included the clinical features, treatments, and outcome of each case.

Results: The majority of envenomations occurred during the spring and summer months. Nine of the 31 dogs were struck two to four times with the resulting lesions characterized as hemorrhagic lymphedema. Twenty-eight strikes $(63.6 \%)$ were to the head, including the ears and tongue; six $(13.6 \%)$ were to the neck; five $(11.4 \%)$ were to the forelimbs and prescapular regions; three $(6.8 \%)$ were to the thorax or abdomen; and two $(4.5 \%)$ were to the hindlimbs. Six of the 31 dogs did not survive, with three being euthanized and three dying spontaneously. The length of hospital stay ranged from $14 \mathrm{~h}$ to 23 days, with a mean of 4.3 days and a median of 2.5 days. Elapsed time from envenomation to presentation at the referring veterinarian or the UFVMC ranged from $15 \mathrm{~min}$ to over $12 \mathrm{~h}$ with the majority within the first $4 \mathrm{~h}$. Three of the dogs that died received antivenin and three did not. Twenty-two of the 25 survivors received mixed crotalid polyvalent antivenin (from one to ten vials; mean, 4.0 vials; median, four vials) and three did not. Other treatments included intravenous isotonic crystalloid fluids, antibiotics, blood products, and glucocorticoid drugs (majority given one time by the referring veterinarian). Thirteen (42\%) of the $31 \mathrm{dogs}$ had pathologic cardiac arrhythmias (premature ventricular contractions, ventricular tachycardia, and ventricular fibrillation), either at presentation or during hospitalization. Twenty-five (81\%) of 31 dogs had hematologic disorders, including defibrination, elevated fibrin split products, hemolytic anemia (with hemoglobinuria), thrombocytopenia, prolonged clotting times, or combinations of these abnormalities.

Discussion and Conclusion: Dogs envenomated by the Eastern diamondback rattlesnake can suffer life-threatening consequences associated with hypovolemia, systemic bleeding, and cardiac arrhythmias. The most important treatment is isotonic intravenous fluids and crotalid polyvalent antivenin.

\section{BLACK WIDOW SPIDER BITES IN REPRODDUCTIVE- AGE WOMEN AND PREGNANCY}

Wolfe $\mathrm{MD}^{(1)}$, Rayburn $\mathrm{WF}^{(1)}$, Seifert $\mathrm{SA}^{(2)}$.

1. University of New Mexico Division of Maternal-Fetal Medicine, Albuquerque, NM, USA

2. New Mexico Poison \& Drug Information Center, Albuquerque, NM, USA

mdwolfe@salud.unm.edu 
Background: Black widow spider envenomation can cause significant systemic morbidity. The objectives of this study were to report the prevalence of such bites in reproductive-age women reported at US poison centers and to evaluate any differences in treatment administered to pregnant and nonpregnant individuals.

Methods: This retrospective observational study involved a review of the database of the American Association of Poison Control Centers for the period 2003-2007. Only single human exposures to black widow spiders were included. Group differences were analyzed using Chi-square testing with Yates Correction.

Results: There were 12,640 human black widow spider exposures, and envenomations were reported by all 61 poison centers. A total of $8,445(67 \%)$ of the cases were reported to centers in the southern USA as defined by latitude at or below $37 \ddot{y}$. A total of 2,841 (22\%) involved women of reproductive age (15-45 years old). Of these, 97 (3\% of reproductive-age women and $1 \%$ of all bites) were pregnant women. Gestational ages ranged from 4 to 40 weeks. Documented treatment with antivenom ( $1.0 \%$ vs. $1.8 \% ; p=0.87)$, benzodiazepines $(9.3 \%$ vs. $9.1 \%$; $p=0.94)$, antibiotics ( $3.1 \%$ vs. $3.3 \%$; $p=0.92)$, and calcium $(2.1 \%$ vs. $1.8 \% ; p=0.87)$ were not different between pregnant and nonpregnant patients, respectively. Use of antihistamines was more commonly documented in pregnant women than in nonpregnant individuals $(10.3 \%$ vs. $4.9 \%$; $p=$ 0.025). Compared with nonpregnant victims, pregnant patients were more likely to not be managed on site $(p<0.001$, OR 0.4 ; 95\% CI 1.5-4.6) but instead to be either treated and released $(p<0.001$; OR $2.2 ; 95 \%$ CI $1.4-3.3)$ or admitted to a healthcare facility $(p<0.001$; OR $2.64 ; 95 \%$ CI $1.5-4.6)$. Other levels of care were not significantly different (Table 1). Pregnant women were more likely to be coded as having minor effects $(p=0.04$; OR $1.6 ; 95 \%$ CI $1.0-2.4)$ and less likely to be coded as having no effects $(p=0.013$; OR 0.6 ; $95 \%$ CI $0.4-0.9$ ). There were no significant differences in "moderate" or "major" effects outcome codes. There were no deaths (Table 2).

Discussion: Black widow spider bites are more commonly reported to poison centers in Southern states. They are rare in pregnant women. Data for long-term pregnancy outcomes following this envenomation are not currently available. Pregnant patients may be more likely to seek care and thus have higher rates of being treated and released or to be admitted to a healthcare facility than nonpregnant patients. Demographic differences in presentation likelihood may also affect outcome coding, but outcome codes of moderate or major effects are the same between pregnant and nonpregnant patients. Conclusions: According to a national poison control center database, approximately 570 reproductive-age women are bitten annually by black widow spiders with 20 persons being known to be pregnant. The numbers of pregnant patients seeking care and being hospitalized are greater than nonpregnant patients, but therapeutic interventions and outcomes were not generally different. Studies of pregnancy outcomes are required.

Table 1. Level of care provided for black widow spider envenomations

\begin{tabular}{llll}
\hline $\begin{array}{l}\text { Level of } \\
\text { care }\end{array}$ & $\begin{array}{l}\text { Treated and } \\
\text { released }\end{array}$ & $\begin{array}{l}\text { Admit to } \\
\text { critical care }\end{array}$ & $\begin{array}{l}\text { Admit to } \\
\text { non-critical } \\
\text { care }\end{array}$ \\
\hline Pregnant & $35(36.1 \%)$ & $2(2.1 \%)$ & $13(13.4 \%)$ \\
Non-pregnant & $2,600(20.7 \%)$ & $250(2.0 \%)$ & $569(4.5 \%)$
\end{tabular}

\begin{tabular}{lll}
\hline $\begin{array}{l}\text { Refused } \\
\text { referral/no } \\
\text { show }\end{array}$ & $\begin{array}{l}\text { Lost to } \\
\text { follow-up/AMA }\end{array}$ & $\begin{array}{l}\text { Managed on-site } \\
\text { (non-healthcare } \\
\text { facility) }\end{array}$ \\
\hline $4(4.1 \%)$ & $5(5.2 \%)$ & $38(39.2 \%)$ \\
$405(3.2 \%)$ & $625(5.0 \%)$ & $8,093(64.5 \%)$ \\
\hline
\end{tabular}

Table 2. Outcome codes of black widow spider envenomations

\begin{tabular}{cccccc}
\hline $\begin{array}{c}\text { Outcome } \\
\text { code }\end{array}$ & Major & Moderate & Minor & $\begin{array}{c}\text { No } \\
\text { effect }\end{array}$ & $\begin{array}{c}\text { Unable to } \\
\text { follow }\end{array}$ \\
\hline Pregnant & 2 & 16 & 36 & 37 & 6 \\
& $(2.1 \%)$ & $(16.5 \%)$ & $(37.1 \%)$ & $(38.1 \%)$ & $(6.2 \%)$ \\
Non- & 67 & 1736 & 3447 & 6486 & 806 \\
pregnant & $(0.5 \%)$ & $(13.8 \%)$ & $(27.5 \%)$ & $(51.7 \%)$ & $(6.4 \%)$ \\
\hline
\end{tabular}

\section{VENOMOUS SNAKE TAXONOMY: WHY TOXINOLOGISTS AND CLINICIANS SHOULD TAKE AN INTEREST}

Wüster W.

School of Biological Sciences, Bangor University, Bangor, UK w.wuster@bangor.ac.uk

Introduction: Taxonomy and toxinology have a longstanding fraught relationship, whereby novel taxonomic insights often fail to be absorbed by the toxinological community. However, toxinologists have much to gain from taking an interest in the systematics of the animals they work with. In this talk, I will explore two impacts of taxonomy on toxinological research. 
Taxonomy as a label: the beginning of wisdom is calling things by their right names: At its most basic, taxonomy provides labels for biodiversity. Understanding what species' venom one is working with is an obvious and fundamental requirement in toxinology. However, the combination of widespread "taxonomic apathy" among toxinologists and the rapid accumulation of novel insights into the taxonomy of snakes seriously impedes the interpretability of much toxinological work, which I illustrate through a survey of the recent taxonomic literature.
Snake phylogeny: a tool for insights into venom evolution: The remit of systematics and taxonomy goes far beyond simply naming things. Central to our understanding of the diversity of life and the evolution of its traits is the set of evolutionary relationships linking all organisms: the tree of life. Including a phylogenetic perspective in toxinological research has a number of potential benefits, including providing a road map for bioprospecting for toxins of pharmacological or biomedical interest and as an essential underpinning to understand the evolution of venom and venom composition in snakes. 